OPEN ACCESS

Edited by:

Katrin Schroeder,

Italian National Research Council, Italy

Reviewed by:

Mahendra Verma

Indian Institute of Technology Kanpur,

India

Konstantin Alex Korotenko,

P.P. Shirshov Institute of Oceanology

(RAS), Russia

*Correspondence:

Fahad Al Senafi

fahad.alsenafi@ku.edu.kw

Specialty section: This article was submitted to

Physical Oceanography,

a section of the journal

Frontiers in Marine Science

Received: 31 October 2019 Accepted: 13 December 2019

Published: 14 January 2020

Citation:

Al Senafi F and Anis A (2020) Internal Waves on the Continental Shelf of the

Northwestern Arabian Gulf.

Front. Mar. Sci. 6:805.

doi: 10.3389/fmars.2019.00805

\section{Internal Waves on the Continental Shelf of the Northwestern Arabian Gulf}

\author{
Fahad Al Senafi ${ }^{1 *}$ and Ayal Anis ${ }^{2}$ \\ ${ }^{1}$ Department of Marine Science, College of Science, Kuwait University, Kuwait City, Kuwait, ${ }^{2}$ Department of Oceanography, \\ Texas A\&M University, College Station, TX, United States
}

Turbulent fluxes and mixing due to internal waves (IWs) play a major role in transporting nutrients, affecting biological productivity and water-borne constituents such as contaminants and sediments. To better understand IWs on the continental shelf of the northwestern Arabian Gulf, off the coast of Kuwait, we conducted a study to examine the characteristics of these waves, and the associated energy cascade from IWs to turbulence. The study was conducted during midsummer (15 to 27 July, 2017), collected spatial transects and time series measurements at five moorings. Continuous turbulence profiles were taken at four locations in the vicinity of the moorings. Measurements of temperature, salinity, currents, turbidity, chlorophyll $a$, and turbulence reveal that IW activity was consistent with the diurnal and semidiurnal tidal cycles. Based on cross shore tracking of the IWs, it was estimated that the IWs propagated toward the coast at an average speed of $0.31 \mathrm{~m} / \mathrm{s}$. IW amplitudes ranged from 7 to $9 \mathrm{~m}$ and were observed to generate intense mixing $\left(>10^{-7} \mathrm{~W} / \mathrm{kg}\right)$. In addition, we examined nighttime convective conditions driven by surface buoyancy flux which were estimated to contribute up to $70 \%$ of the turbulence kinetic energy (TKE) production. The results presented here shed new light on IW characteristics in the Northern Arabian Gulf, and offer the first detailed study of these waves in this region.

Keywords: Arabian (Persian) Gulf, internal waves, internal tides, Kuwait, turbulence

\section{INTRODUCTION}

IWs are gravity waves in the interior of the flow, analogous to the surface gravity waves and propagate in fluids with a stable density stratification. In aquatic environments, stratification is related to the formation of layers of water of distinct physical properties (such as temperature and/or salinity) due to limited vertical mixing. Wave motion arises from perturbations that cause parcels of fluid to oscillate up or down when they encounter restoring buoyancy forces resulting from the stable density stratification.

The fluxes and turbulent mixing generated by IWs may be vital for transporting nutrient-rich waters into coastal ecosystems (Laurent et al., 2012). They also impact biological productivity (for example, in coral reefs) as well as sediment transport (Quaresma et al., 2007). Thus, IWs provide a crucial link between large scales into which most energy is produced and the small scales at which energy dissipation occurs. As a result, IWs play a major role in the transport of momentum, the production of mixing, and the dissipation of energy in regions far from their generation (e.g., Lamb and Farmer, 2011). 
Continental shelves are complex environments and are affected by a variety of physical processes and scales which may include barotropic tides, mesoscale and sub-mesoscale variability such as eddies, and upwelling and downwelling. IWs, which are ubiquitous in continental shelves and coastal waters, are of particular dynamic significance in such regions and may develop into sharp fronts in which the pycnocline can dramatically shoal in just a few minutes. These waves may have horizontal currents with magnitudes of up to $1 \mathrm{~m} / \mathrm{s}$ and thus are strong enough to significantly affect the navigation of vessels (Apel, 2002). Vertical currents may reach $0.5 \mathrm{~m} / \mathrm{s}$, posing significant problems for subsurface navigation and structures, such as those associated with offshore energy development (Laurent et al., 2012).

IWs may receive their energy from tide-topography interactions (Wunsch and Ferrari, 2004) that inject energy into IWs of tidal frequency (also known as internal tidal waves). Low-mode IWs generated by tide-topography can propagate thousands of kilometers from their source in the deep ocean (Alford, 2003; Kunze et al., 2012) and can behave in an unpredictable manner where their phase and amplitude differ from surface tides (Nash et al., 2012). The fate of these waves (e.g., through breaking) and their effects on their environment are equally complex.

Compared to turbulence studies in the open ocean e.g., Moum (1996) or the continental slope e.g., Moum et al. (2002), Kelly et al. (2010), there has been much less exploration of turbulent mixing on shallow continental shelves. The studies that have been conducted were at locations with relatively rich topographic features and weak vertical stratification. One report on the Scotian Shelf by Sandstrom and Oakey (1995) described increased vertical shear due to the presence of IWs that, in turn, enhanced turbulent kinetic energy (TKE) dissipation rates (proxy for mixing intensity) in excess of $10^{-7}$ $\mathrm{W} / \mathrm{kg}$, accounting for $20 \%$ of the baroclinic energy loss. In a study in the Irish Sea, Simpson et al. (1996) found that TKE dissipation rates in excess of $10^{-5} \mathrm{~W} / \mathrm{kg}$ exhibited quarterdiurnal $\left(\mathrm{M}_{4}\right)$ variability with a pronounced $4 \mathrm{~h}$ phase lag. Similarly, a study by Shroyer et al. (2011) over New Jersey's shelf demonstrated that IWs that receive energy from barotropic tides can propagate irregularly and not consistently be tidal phaselocked. Turbulent mixing on the Oregon shelf was found to be strongly influenced by topographic roughness enhancing TKE dissipation rates to $10^{-4} \mathrm{~W} / \mathrm{kg}$ reducing the energy available for IW generation (Nash and Moum, 2001). Whereas, the surface tidal displacement of $0.92 \mathrm{~m}$ at the Oregon slope produced IW energy flux of $500 \mathrm{~W} / \mathrm{m}$ (Kelly et al., 2010). In two studies conducted on the Monterey Bay Shelf by Carter et al. (2005) and Kunze et al. (2012), elevated TKE dissipation rates of up to $10^{-6}$ and $10^{-7} \mathrm{~W} / \mathrm{kg}$, respectively, were found to arise mainly due to the proximity to Monterey Bay Canyon with the IWs accounting for $50 \%$ of the energy loss in the upper $150 \mathrm{~m}$. In contrast to the studies listed above, the results presented here describe IW characteristics on a shallow continental shelf, and offer the first detailed study of these waves in the Arabian Gulf (also known as the Persian Gulf; hereafter we use Gulf).

The Gulf is a semi-enclosed marginal sea that is $\sim 1,000 \mathrm{~km}$ long, has a maximum width of $370 \mathrm{~km}$, and a surface area of
$239,000 \mathrm{~km}^{2}$. On average, the Gulf is $\sim 35 \mathrm{~m}$ deep (Nezlin et al., 2010). General circulation in the Gulf results from a combination of wind and thermohaline driven flow, mesoscale eddy fields, and constricted water exchange with the open ocean through the Strait of Hormuz. The northern part of the Gulf (the location of our study region) is dominated by wind forcing and limited riverine input (mainly from the Euphrates and Tigris rivers) at the head of the Gulf. The wind-driven response of the Gulf appears to occur through an adjustment of the pressure field producing a general downwind surface flow (Reynolds, 1993).

In the northern Gulf, the frequent dry wind from the northwest-(known as Shamal, Rao et al., 2003) -is relatively cold (near $0^{\circ} \mathrm{C}$ ) in winter and extremely hot in summer (average temperature of $41^{\circ} \mathrm{C}$ and a maximum of $51^{\circ} \mathrm{C}$ ). The Shamal can cause intense sand and dust storms (Al Senafi and Anis, 2015). Southeasterly winds, which are usually hot and humid, are common in July and August. High evaporation rates, combined with restricted exchange of seawater with the open ocean, leads to the formation of a highly saline (> $41 \mathrm{PSU}$ ) and dense water mass $\left(>1,030 \mathrm{~kg} / \mathrm{m}^{3}\right)$ known as Gulf Deep Water, or GDW, in the northern part of the Gulf, which eventually spills into the Indian Ocean (Swift and Bower, 2003). In addition to the Red Sea, the GDW is the second salty water mass that spill into the Indian Ocean. This water mass which forms in the northern Gulf affects global ocean circulation patterns that are linked to the Indian Ocean. An improved understanding of the IW climate and their relation to mixing in this area are thus of major importance in determining the production and physical properties of the GDW and provided the impetus for this study.

Our study focused on IWs on the continental shelf in the northwestern Gulf off the Kuwaiti coast. Specific objectives were to:

- Characterize the IW climate using spatial transects and time series measurements from an array of moored instruments and from turbulence profiling;

- Quantify the IW energy and multi-scale energy cascade from IWs to turbulence under various forcing conditions;

- Provide a quantitative picture of physical oceanographic and surface meteorological background conditions during summer in the northwestern Gulf in the context of the IW climate and mixing. It is expected that this information will allow improvement of regional and global circulation models;

- Relate water quality parameters (turbidity and chlorophyll $a$ ) throughout the water column in this region to the background conditions and IW climate.

This paper is structured as follows. In section 2, we describe the methodology used to collect the time-series measurements and the cross-shelf turbulence profiling. The results and discussion presented in section 3 are organized as follows: the meteorological conditions are described in sections 3.1 and 3.2 analyzes the thermal and current structures to determine internal wave features such as pycnocline oscillations, wave speeds and amplitudes; section 3.3 discusses the turbulence profiles to quantify the IW energy cascade and analyzes the effects of IWs during convective conditions. Summary and conclusions are given in section 4 . 


\section{RESEARCH DESIGN AND THEORETICAL FRAMEWORK}

IWs are detectable through the changes in sea temperature, salinity, density, currents, and the resulting turbulence the IWs may induce. We conducted observations of IWs across and along the Kuwaiti coastal shelf off Fintas, a southern suburb of Kuwait City $\left(29^{\circ} 10^{\prime} 09.45^{\prime \prime} \mathrm{N}, 48^{\circ} 09^{\prime} 18.70^{\prime \prime} \mathrm{E}\right)$. Figure 1 shows the study region and the experimental setup. This site is located along a gently sloping seabed with an average slope angle of $0.23^{\circ}$ and with no complex topographic features making it ideal to study IW propagation. The field work was conducted over a period of 12 days between 15 and 27 July 2017 to capture a complete succession of neap and spring tidal cycles during the stratified summer period.

Two observational approaches were used to obtain spatial and temporal data and derive the structure of the IWs: time series measurements and cross-shelf profiling. We obtained estimates of physical and turbulence parameters by applying the computation methods described below.

(1) Time series measurements: Five moorings (M2 to M6; Figure 1) were deployed along the sloping incline perpendicular to the coastline to capture IWs at various stages of disintegration and to track IW features over time and space. The orientation of the mooring array was designed to be in the expected main propagation direction of shoreward-moving IWs, i.e., along a line perpendicular to the coastline. To adapt the mooring array for optimal measurement of the disintegrating IWs, the five moorings were deployed in an arrangement that used exponentially increasing spacing between moorings (Figure 1). The exponential spacing of the moorings was designed to improve horizontal spatial resolution upon approaching the coastline where we expected much of the dissipation to occur due to the increase in the slope angle. The shallowing bathymetry in this region has a slope that increases roughly as an exponential function of the distance from the coastline. We note that eventually small adjustments were made during moorings deployment based upon the vessels' depth sounder. The spacing between moorings changed from $1,150 \mathrm{~m}$ (at a nominal water depth of $12 \mathrm{~m}$ ) to 5,050 $\mathrm{m}$ (at a nominal water depth of $25 \mathrm{~m}$ ) from the coast to the open sea off Fintas. Moorings were instrumented with bottom-mounted upward-looking Acoustic Doppler Current Profilers (ADCPs), Conductivity-TemperatureDepth loggers (CTDs) and temperature loggers positioned at various depths between the sea surface and seabed (Table 1).

Furthermore, a bottom mounted Acoustic Doppler Velocimeter (ADV) at M2 (nominal water depth of $11.7 \mathrm{~m}$ ) sampled 3 beam velocities and pressure at $16 \mathrm{~Hz}$ in bursts of 2,048 samples (duration of $128 \mathrm{~s}$ with $17 \mathrm{~min}$ intervals between bursts). Velocity data with signal-to-noise-ratios (SNR) $>10 \mathrm{~dB}$ and correlation values $>70 \%$ (Rusello, 2009) were despiked (Islam and Zhu, 2013). A total of 1001 (95\%), out of 1,052 recorded bursts, passed quality control and were used for further analysis and estimates of TKE dissipation rates, $\epsilon$.

The classical Kolmogorov -5/3 law allows estimation of $\epsilon$, from the velocity wavenumber spectra in the inertial subrange

$$
F_{i i}(k)=\alpha_{i} \epsilon^{2 / 3} k^{-5 / 3}
$$

where $F_{i i}(k)$ is the velocity wavenumber spectrum, $k$ is the wavenumber in the longitudinal (streamwise) direction, $i$ represents the direction of velocity fluctuations $(i=1$ is the longitudinal (streamwise) direction, $i=2$ is the transverse (spanwise) direction, and $i=3$ is the vertical direction), and $\alpha_{i}$ is a constant (Saddoughi and Veeravalli, 1994). In this study we used the vertical velocity $(i=3)$ for power spectrum density (PSD) estimates. Due to the ADV's beam configuration the vertical velocity exhibits a noise level lower by a factor of $\sim 10$ compared to the

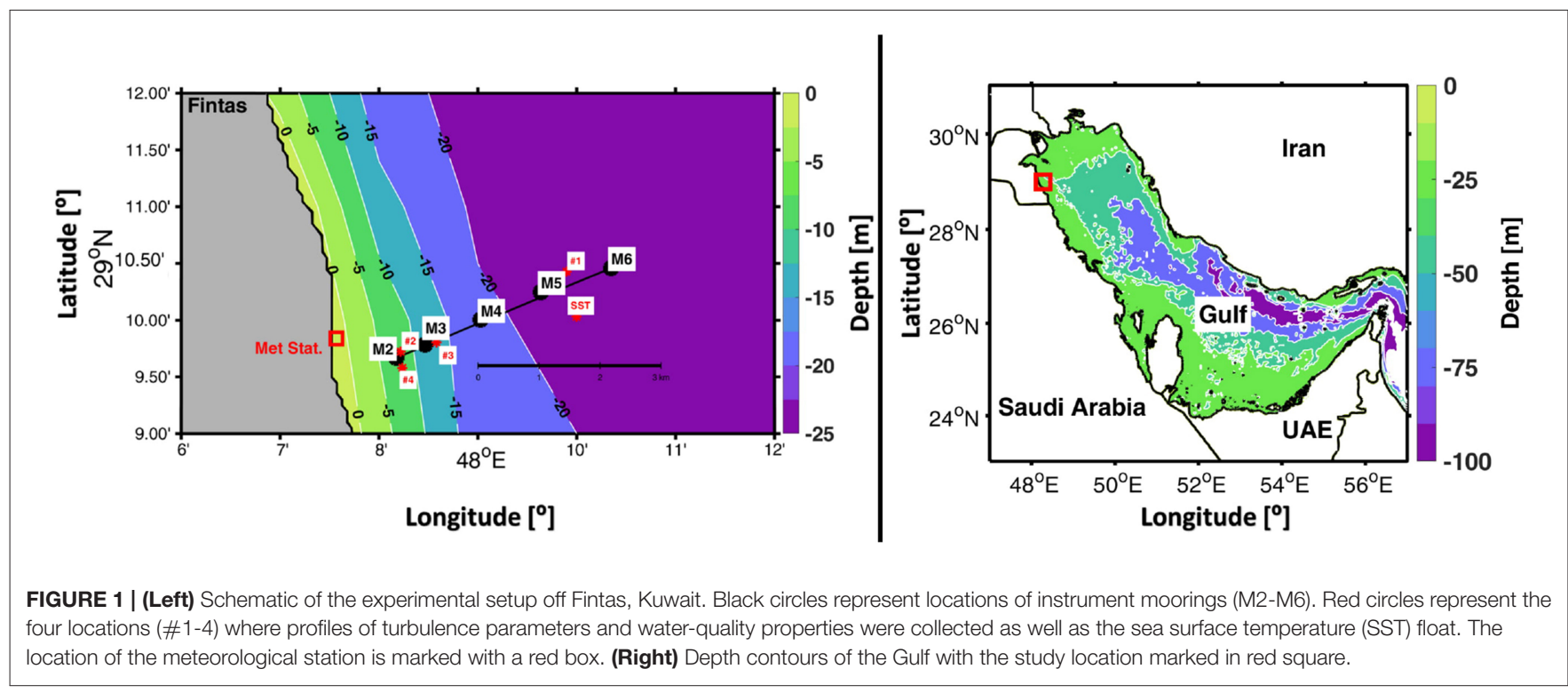


TABLE 1 | Mooring and instrument details.

\begin{tabular}{|c|c|c|c|c|c|}
\hline $\begin{array}{l}\text { Name } \\
\text { of mooring }\end{array}$ & $\begin{array}{l}\text { Distance } \\
\text { offshore [m] }\end{array}$ & $\begin{array}{l}\text { Water depth } \\
{[\mathrm{m}]}\end{array}$ & $\begin{array}{l}\text { Name } \\
\text { of instruments }\end{array}$ & $\begin{array}{l}\text { Sampling intervals } \\
\text { and frequencies }\end{array}$ & $\begin{array}{l}\text { Vertical position } \\
\text { (distance from seabed) [m] }\end{array}$ \\
\hline SST & 4,125 & 21 & 1 Onset temp. logger & $60^{\prime \prime}$ & Surface float \\
\hline M2 & 1,150 & 11.7 & 1 Nortek ADV & $\begin{array}{l}\text { Bursts at } 16 \mathrm{~Hz} \text {, } \\
2048 \text { samples every 17' }\end{array}$ & Bottom boundary layer \\
\hline M3 & 1,650 & 13.8 & $\begin{array}{l}2 \mathrm{MHz} \text { Nortek ADCP } \\
5 \text { RBR solo temp. loggers } \\
1 \text { PME DO logger } \\
1 \text { RBR solo pressure logger }\end{array}$ & $\begin{array}{l}\text { Profiles at } 15^{\prime \prime} \text { intervals } \\
2 \mathrm{~Hz} \\
60^{\prime \prime} \\
2 \mathrm{~Hz}\end{array}$ & $\begin{array}{l}0.5 \text { ( } 20 \text { cells }) \\
2.5,5,7.5 \\
9.5,11.5 \\
8.5 \\
0.68\end{array}$ \\
\hline M4 & 2,650 & 18.9 & $\begin{array}{l}7 \text { RBR solo temp. loggers } \\
1 \text { PME DO logger }\end{array}$ & $\begin{array}{l}2 \mathrm{~Hz} \\
60^{\prime \prime}\end{array}$ & $\begin{array}{l}1.5,3.5,5.5,7.5 \\
9.5,11.5,13.5 \\
8.5\end{array}$ \\
\hline M5 & 3,750 & 24 & $\begin{array}{l}5 \text { RBR solo temp. loggers } \\
1 \text { RBR duet temp. and depth } \\
3 \text { RBR solo fast temp. } \\
\text { 1 PME DO logger }\end{array}$ & $\begin{array}{l}2 \mathrm{~Hz} \\
16 \mathrm{~Hz} \\
16 \mathrm{~Hz} \\
60^{\prime \prime}\end{array}$ & $\begin{array}{l}3,6,8,10,19 \\
0.72 \\
12,14,16 \\
13.2\end{array}$ \\
\hline M6 & 5,000 & 26.4 & $\begin{array}{l}1 \mathrm{MHz} \text { Nortek ADCP } \\
8 \text { Onset temp. loggers } \\
1 \text { RBR solo pressure logger } \\
1 \text { RBR CTD logger } \\
1 \text { RBR CT logger }\end{array}$ & $\begin{array}{l}\text { Profiles at } 15^{\prime \prime} \text { intervals } \\
60^{\prime \prime} \\
2 \mathrm{~Hz} \\
0.25 \mathrm{~Hz} \\
0.5 \mathrm{~Hz}\end{array}$ & $\begin{array}{l}0.5 \text { (50 cells) } \\
2,4,6,8,10, \\
14.25,18.50,21 \\
0.7 \\
16 \\
12.5\end{array}$ \\
\hline
\end{tabular}

horizontal components (Voulgaris and Trowbridge, 1998; Khorsandi et al., 2012). For isotropic turbulence, $\alpha_{3}=0.65$ (Pope, 2000).

Due to possible contamination of the velocity spectra by surface waves $\epsilon$ was estimated using a modified Kolmogorov $-5 / 3$ formulation proposed by Trowbridge and Elgar (2001):

$$
S_{i i}(f)=\frac{12}{55} \alpha U^{2 / 3} \epsilon^{2 / 3} f^{-5 / 3} I\left(\frac{\sigma}{U}, \theta\right),
$$

where $I$ is a function of $\sigma$, the standard deviation of the horizontal velocities, $U, \theta$ is the angle between the current and waves, and $\alpha=1.5$ is the one-dimensional Kolmogorov constant (Saddoughi and Veeravalli, 1994). This modified method has previously been shown to be effective when applied to ADV measurements in the study of IW energy transport by Moum et al. (2007).

Using the 1001 bursts that passed SNR and Correlation quality control criteria, $\epsilon$ was computed using a linear fit in log-space to the one-dimensional velocity frequency spectrum. An estimate of $\epsilon$ was rejected when the fitted slope was outside an interval of -2.27 and -1.07 . This criteria has been accepted and used by previous studies e.g., Sato et al. (2014) who measured IW's and turbulence in Patricia Bay, Canada. Using this approach, a total of 994 out of the 1,001 bursts (94\%) were deemed to be suitable to estimate $\epsilon$. An example of a burst that passes the quality control and fitting criteria is presented in Figure 2.

Four moorings (M3-M6) were equipped with RBR conductivity-temperature (CT) loggers, Onset light sensors, Onset temperature sensors, and PME dissolved oxygen (DO) loggers equipped with wipers to help prevent marine fouling (see Table 1 for details). Additionally, the moorings included
17 fast-response RBR Solo temperature sensors recording at $2 \mathrm{~Hz}$ and three recording at $16 \mathrm{~Hz}$. Each of the 20 fast-response temperature sensors was mounted on a winged frame which oriented the sensors into the flow to minimize possible flow disturbances from the mooring line and instrument wake. Another fast-response temperature-pressure sensor recording at $16 \mathrm{~Hz}$ was attached to the bottom pod at M5, pointing upward. Spectral estimates of temperature fluctuations measured by the moored sensors provided details on the spatiotemporal evolution of mixing activity in the water column (details in section 3.2.4).

Our interest in this study are the energetic tidally forced IW's which, based on spectral analysis (details in section 3.2.2), are limited to a period of $3 \mathrm{~h}$ ( $M_{8}$ tidal harmonic). Thus, prior to further analysis, the ADCP velocity and temperature profiles were filtered using a second-order Butterworth low-pass filter to eliminate processes with time scales less than $2 \mathrm{~h}$ but retain low tidal modes (e.g., $M_{8}-O_{1}$ tidal harmonics). Furthermore, the time series of profiles of the vertical velocity component, $w$, measured by the ADCP were used to provide a direct estimate of the IW kinetic energy $(K E)$,

$$
K E=\frac{1}{2} \overline{w^{2}}
$$

As shown in Richards et al. (2013), using the vertical velocity component effectively isolates the large horizontal background processes and magnifies the vertical processes generated by IWs.

As part of the experiment, we deployed a full suite of meteorological sensors on a mast mounted at the pier of Kuwait University's Marine Science Center in Fintas (800 $\mathrm{m}$ from M2; Figure 1). The station provided measurements of surface meteorological parameters (air temperature and 

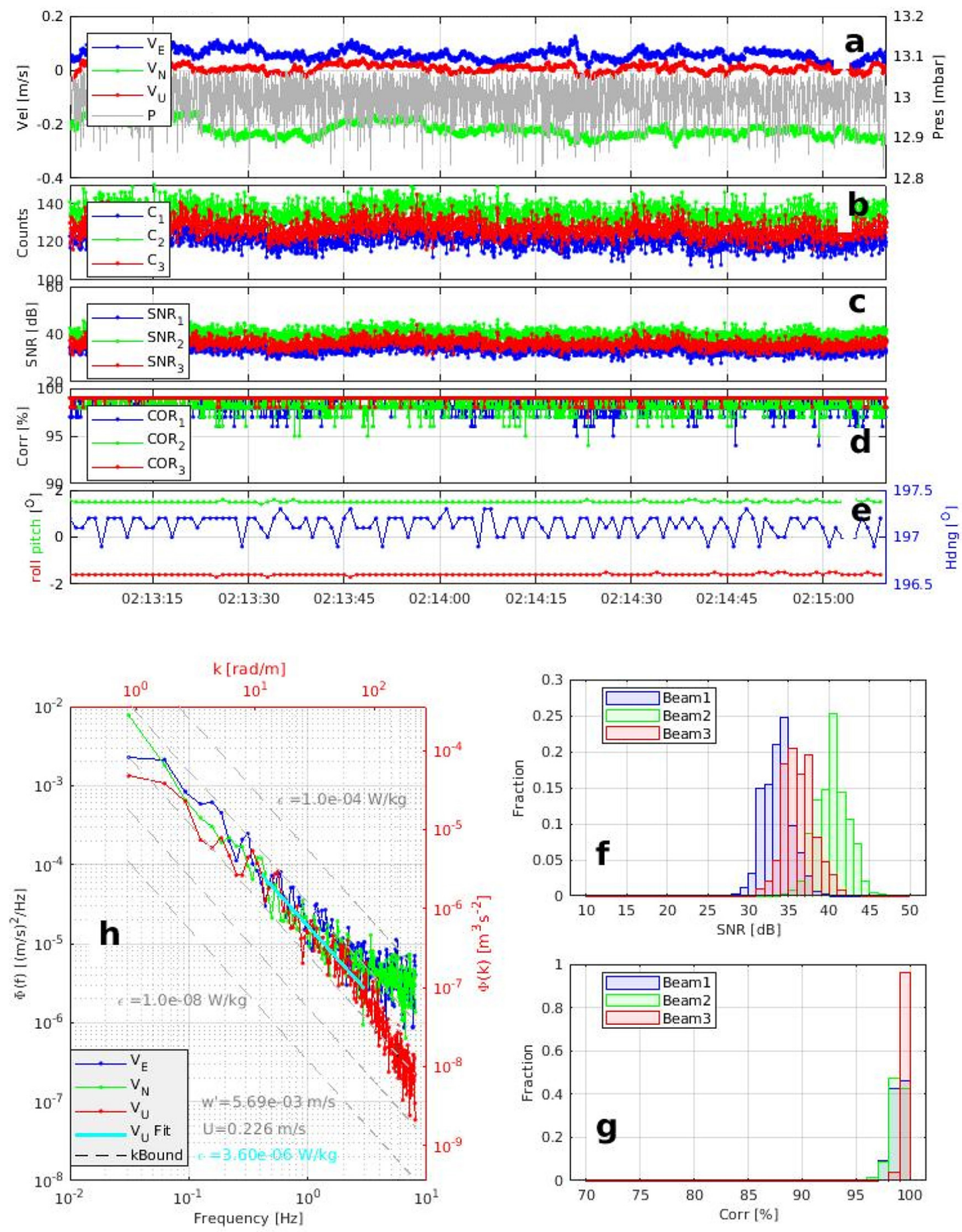

FIGURE 2 | ADV burst example, 15 July, 2017, mooring M2. (a) Traces of east-west (blue), north-south (green), and vertical (red) velocity components, and of pressure (gray) as a function of time (the entire burst spans 128 s); (b) counts (signal strength) for each beam; (c) SNR for each beam; (d) correlations for each beam; (e) roll (red), pitch (green), and heading (blue) (allows detection of possible motion of the bottom pod); (f) histogram of SNR for each beam; (g) histogram of correlations for each beam; (h) PSD of the east-west (blue), north-south (green), and vertical (red) velocity components. Sloping broken gray lines represent values of $\epsilon$ from $10^{-8}$ to $10^{-4} \mathrm{~W} / \mathrm{kg}$. The solid cyan line represents a fit to the PSD of vertical velocity fluctuations.

humidity, wind speed and direction, incoming shortwave and longwave radiation, and barometric pressure) at $1 \mathrm{~min}$ intervals to complement the oceanographic measurements. Net heat flux, $J_{q}^{o}$, and wind stress, $\tau$, were computed from the meteorological measurements following the Coupled Ocean Atmosphere Response Experiment (COARE ver 3.5) formulation 
(Fairall et al., 1996, 2003). From $\tau$ and $J_{q}^{o}$ we computed the Monin Obukhov length scale, $L$, to predict when turbulence might be dominated by wind stress $(L>0)$ or by convective buoyancy loss at the surface $(L \leq 0)$,

$$
L=\frac{-u_{*}^{3}}{\kappa J_{b}^{o}}
$$

where $u_{*}=\sqrt{\tau / \rho}$ is the friction velocity related to wind stress and density, $\kappa=0.4$ is von Karman's constant, and $J_{b}^{o}$ is the surface buoyancy flux (Monin and Obukhov, 1954; Anis, 2006).

(2) Cross-shelf profiling: Free-fall turbulence profiling were carried out with Rockland Scientific's microCTD $(512 \mathrm{~Hz}$ sampling rate) turbulence profiler that allows measurement of small-scale (order $1 \mathrm{~mm}$ ) fluctuations of conductivity, temperature, and current shear from which $\epsilon$ was estimated. The free-fall $(\sim 0.7 \mathrm{~m} / \mathrm{s})$ profiler, took measurements during the descent. At the end of each profile, after the profiler landed on the seabed, it was pulled back to the surface by it's tether line ready to start the next profile. Profiles were taken continuously over the 5-day period-except short breaks to change watch teams-to provide adequate statistics of turbulence parameters throughout the water column. A total of 1,451 profiles were recorded over a 5-day period (15 to 20 July 2017) at the mooring sites (Figure 1; red circles).

Spectra were computed from current-shear measurements of two perpendicularly oriented sensors after being high-pass filtered using a first-order Butterworth filter. The resulting two shear datasets from both sensors were then grouped into 26 overlapping segments each with a vertical bin size of 1.4 m starting from $\sim 1.75 \mathrm{~m}$ depth when the profiler reached it's nominal fall speed. Each segment included 1,024 samples (2 s bins) with 512 sample (50\%) overlap. Each segment was windowed with a generalized Cosine window, and the fast Fourier transform (FFT) calculated.

$$
\epsilon=\frac{15}{2} v \overline{\left(\frac{\partial u}{\partial z}\right)^{2}}=\frac{15}{2} v \int_{0}^{\infty} \Phi(k) d k,
$$

where $v$ is the kinematic viscosity, $\frac{\partial u}{\partial z}$ is the vertical shear of the horizontal velocity and $\Phi(k)$ is the shear spectrum. Noise was removed from the spectra which were then fitted with the empirical Nasmyth spectrum (Nasmyth, 1970; Osborn and Crawford, 1980; Oakey, 1982; Monin and Ozmidov, 1985; Bluteau et al., 2016) from which $\epsilon$ was estimated by integrating the fitted spectrum. A total of 1,218 out of the 1,451 profiles ( $84 \%)$ included estimates of $\epsilon$ for all segments.

An example of a spectrum of a single segment from the two shear probes and the fitted Nasymth spectra are presented in the top panel of Figure 3. The data was collected between 13.2 and $14.6 \mathrm{~m}$ depths (segment 16) at location \#1 at midnight on 16 July, 2017. The increase in spectra for wavenumbers larger than 107 cpm (thin blue and red lines) is due to instrument noise and possible instrument vibration not detected by the accelerometer and was "cleaned" using Goodman's coherent noise reduction algorithm (thick red and blue lines) (Goodman et al., 2006).
To minimize overestimation of $\epsilon$ due to noise, the Nasmyth spectrum was fitted to the observed shear spectrum (black lines) and integrated over a finite range. The finite range was set between 0 and the wavenumber of the spectral minimum $\left(k_{\max }\right)$ that is detected using a low-order polynomial fit (triangles). Using this approach resulted in $\epsilon$ values of 2.9 and $3.7 \times 10^{-7} \mathrm{~W} / \mathrm{kg}$ for the two shear probes. A total of 26 segments was used for each shear probe to construct the $\epsilon$ profiles (Figure 3; bottom panel). $\epsilon$ profiles from both shear probes were found to be in good agreement and for statistical robustness were averaged before further analysis.

The profiler was also equipped with a fluorometer and turbidity probe that provided chlorophyll a concentrations and turbidity profiles. Temperature and conductivity from the profiles was used to compute the density for estimates of the buoyancy frequency, $N^{2}$ (a measure of stratification), and the Richardson number, $R i$, the ratio between $N^{2}$ and vertical shear, $S^{2}$. $R i$ has a theoretical threshold of $R i_{c} \leq 0.25$ for instability, but may range between 0.2 and 1.0, for unstable flows (Galperin et al., 2007), and was used here to quantify water column stability/instability conditions.

\section{RESULTS AND DISCUSSION}

Next we present results of observations from the meteorological station (section 3.1), the five cross-shore mooring stations M2 to M6 (section 3.2), and two locations between the mooring sites where continuous turbulence profiling was conducted (section 3.3) (Figure 1).

\subsection{Meteorological Conditions}

During the 12-day study period, we recorded both continental northwesterly winds and maritime southeasterly winds (directions indicate where the wind is blowing from). The continental northwesterly winds (Figure 4A; red shading) produced drier and hotter conditions with an average relative humidity of 19\% (Figure 4D) and a maximum air temperature of $49.1^{\circ} \mathrm{C}$, on the afternoon of 17 July (Figure $4 \mathrm{C}$ ). This maximum temperature measurement is classified as extremely hot (99th percentile) for the month of July according to a 42 -year (1958-2000) study of extreme temperature events in Kuwait by Nasrallah et al. (2004). The largest measured diurnal temperature range of $11.1^{\circ} \mathrm{C}$ also occurred during the period of northwesterly winds on 17 July.

In contrast, the maritime southeasterly winds (Figure 4A; blue shading) produced up to $90 \%$ relative humidity and cooler conditions, with air temperature ranging from 33 to $40^{\circ} \mathrm{C}$. These winds produced diurnal air temperature ranges as large as $8.6^{\circ} \mathrm{C}$, smaller compared to those during the northwesterly winds. The diurnal air temperature changes throughout the study period caused the sea surface temperature (SST) to follow a well-defined diurnal pattern that varied from 0.6 to $2.7^{\circ} \mathrm{C}$ (Figure 4C).

Despite differences between northwesterly and southeasterly winds in producing abrupt changes in humidity and air temperature in periods as short as $25-\mathrm{min}$, wind speeds were moderate with hourly averages of $3.7 \mathrm{~m} / \mathrm{s}$ (maximum $8.1 \mathrm{~m} / \mathrm{s}$ ) and $2.9 \mathrm{~m} / \mathrm{s}$ (maximum $6.1 \mathrm{~m} / \mathrm{s}$ ), respectively. 

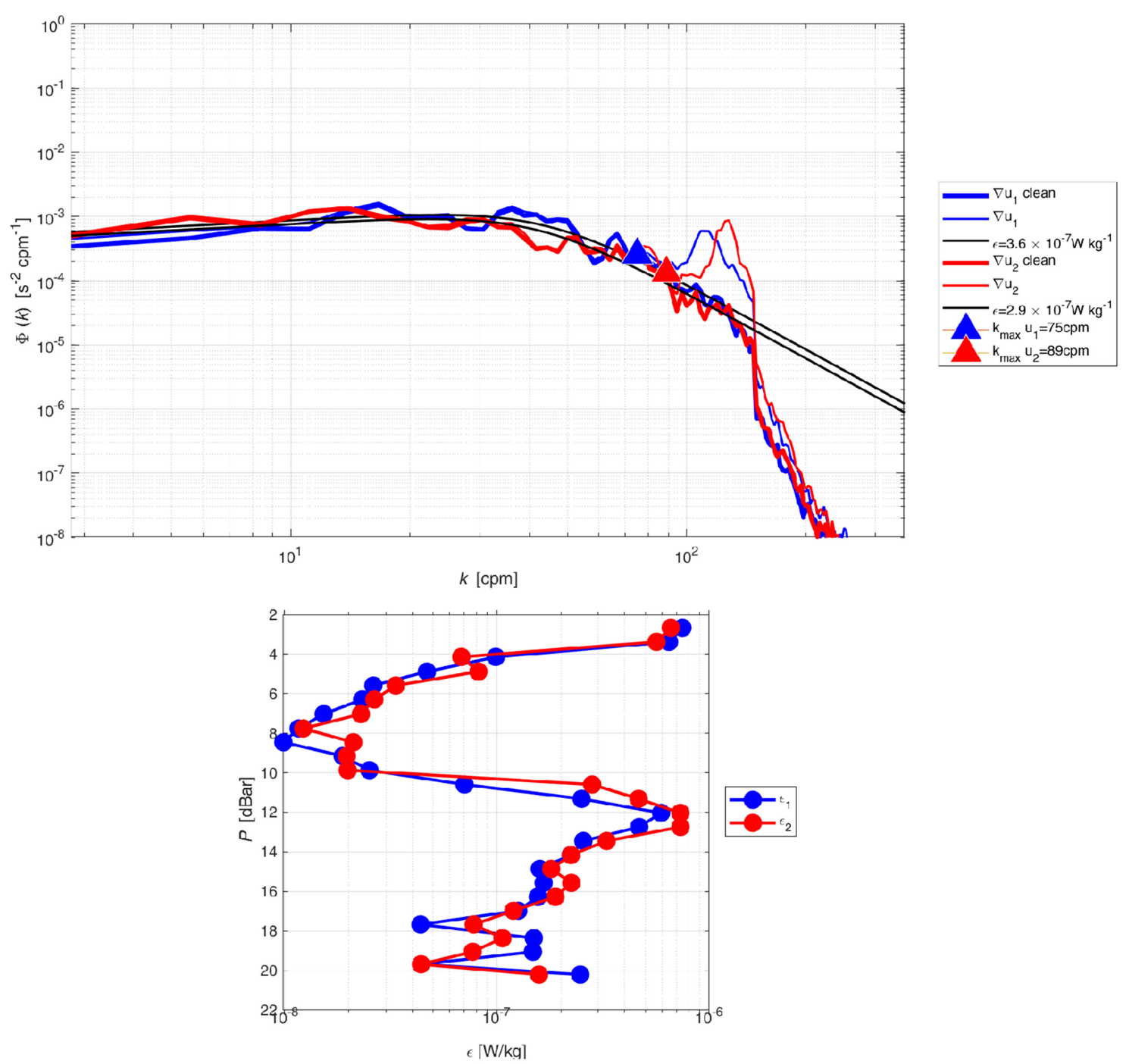

FIGURE 3 | (Top) Example of spectra from the two shear probes, 1 (blue) and 2 (red), of the MicroCTD and the fit to the Nasmyth empirical spectra, July 16. 2017. Spectra before (thin lines) and after (thick lines) noise removal are shown as well. The curved black lines represent the Nasmyth spectra for $\epsilon_{1}=2.9$ and $\epsilon_{2} 3.7 \times 10^{-7}$ W/kg. (Bottom) $\epsilon$ profiles comprised of 26 segments from the two shear probes taken at location \#1.

\subsection{Cross-Shore Mooring Observations}

\subsubsection{Horizontal Currents Background}

The tides in the study region were dominated by a semidiurnal tide with elevations ranging from $0.57 \mathrm{~m}$ (mid-neap, 18 July) to $2.91 \mathrm{~m}$ (mid-spring, $25 \mathrm{July}$ ). This range was consistent across the cross-shore moorings within $0.05 \mathrm{~m}$.

The horizontal current profiles at both ends of the study region (M6 and M3) followed a similar direction but differed in their magnitude. The maximum recorded current speed at M6 was $0.78 \mathrm{~m} / \mathrm{s}$, while that at $\mathrm{M} 3$ was $0.68 \mathrm{~m} / \mathrm{s}$. These maximum current speeds were obtained at mid-depth (between 56 and $65 \%$ of the water-column depth), during mid-ebb ( $3.4 \mathrm{~h}$ after HW), and during mid-spring (afternoon 25 July). Similarly, the north-south (N-S) and east-west (E-W) currents were observed to consistently follow the tidal phase, with maximum current velocities of $0.49 \mathrm{~m} / \mathrm{s}(\mathrm{E}-\mathrm{W})$ and $0.59 \mathrm{~m} / \mathrm{s}(\mathrm{N}-\mathrm{S})$ observed at mid-spring.

\subsubsection{Vertical Currents and IW Energy}

Understanding the dynamics of vertical motions and their variability is crucial for the detection and analysis of IWs. To this end, we focused on the vertical velocity profiles and the $K E$ associated with them as a proxy for wave energy (Equation 7), at both ends of the cross-shore moorings (M6 and M3). The vertical currents at M6 showed a net upward velocity during LW $(\max 4.2$ $\mathrm{mm} / \mathrm{s}$ on 25 July) and a net downward velocity during HW (max $7.8 \mathrm{~mm} / \mathrm{s}$ on 23 July). In contrast, at M3 a net upward velocity was observed during tidal flooding and downward velocity during ebbing, which may suggest that the IW signal maybe a product of tidal constituents. 


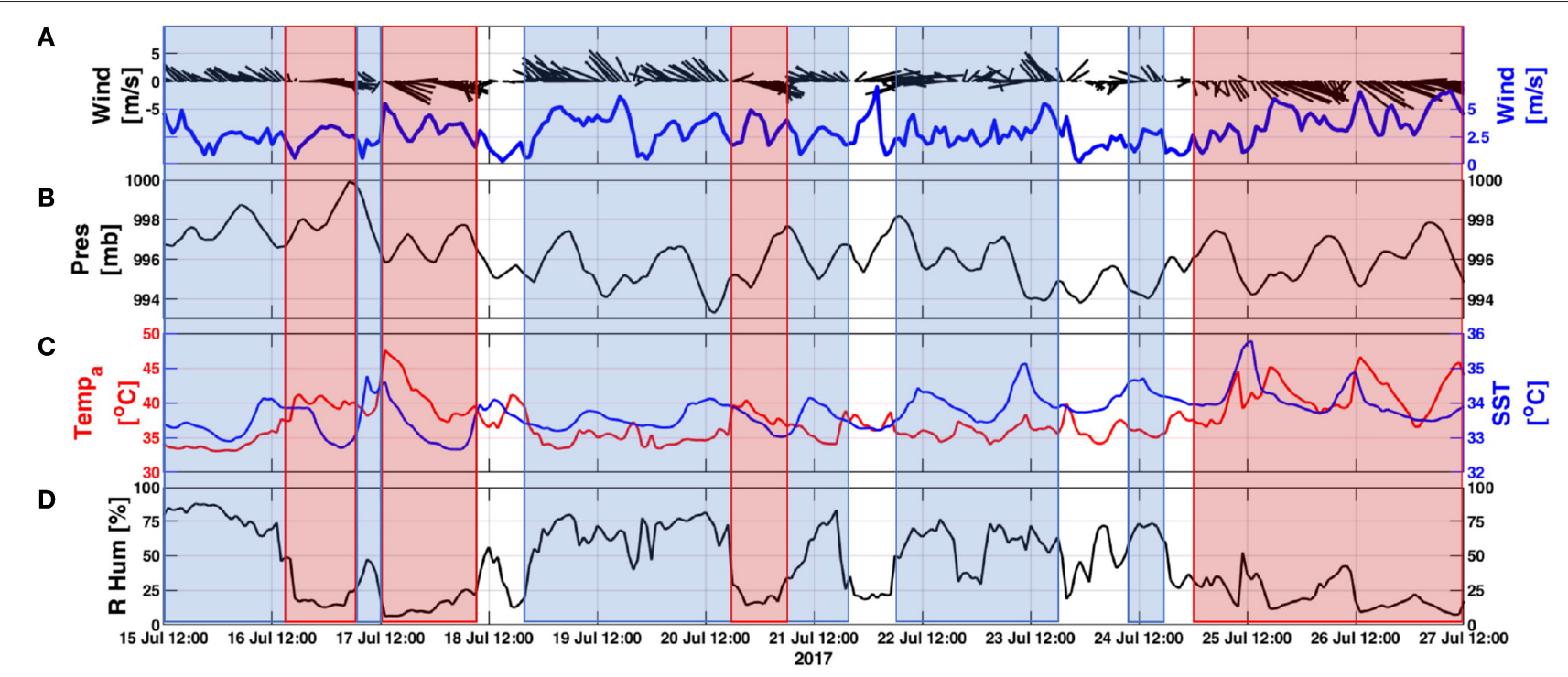

FIGURE 4 | Hourly averages of meteorological measurements from the station located on the coastal pier in Fintas. (A) wind velocity vectors (black) and speed (blue); (B) barometric pressure; (C) air temperature (red) and SST (blue); (D) relative humidity. The blue and red boxes overlaid on each graph represent the southeasterly and northwesterly wind periods, respectively. Time is UTC.

To this end, we estimated vertical velocity spectra from the 15 min ADCPs profiles at both M6 and M3 between 15 and 27 July and compared the vertical velocity oscillation periods with those of the tidal oscillation periods associated with changes in sea surface elevation. This is presented in Figure 5, where elevated pressure spectral levels (green) are associated with possible tidal constituents marked at the top of the figure. The semidiurnal $\left(M_{2}\right.$ and $\left.S_{2}\right)$ and diurnal $\left(O_{1}\right.$ and $\left.K_{1}\right)$ tidal constituents accounted for 95\% of the total tidal kinetic and potential energy. The vertical velocity spectral levels at both M6 (light blue) and M3 (dark blue) associated with these four major tidal constituents were more than twice as large as those of the other constituents. This suggests that IW in the northern Gulf are likely to be a result of the interaction of the $O_{1}, K_{1}, M_{2}$, and $S_{2}$ constituents as they propagate into the region.

The 12-day time series of wave KE at M6 and M3, shown in Figure 6B2, was computed from the observed vertical velocities. The wave energy at M6 closely followed the changes in the tidal phase (Figure 6A), with energy ranging from $8 \times 10^{-8}$ (midneap; 16 July) to $8 \times 10^{-5}$ (mid-spring; 25 July) $\mathrm{m}^{2} / \mathrm{s}^{2}$, indicating more energetic waves during spring phase (Figure 6B1). A similar effect was seen at $\mathrm{M} 3$, where the energy ranged from $1 \mathrm{x}$ $10^{-8}$ (neap) to $4 \times 10^{-6} \mathrm{~m}^{2} / \mathrm{s}^{2}$ (spring), suggesting that the wave energy in deep water exceeds the energy in shallower water.

To further emphasize the relation between the tidal phase and IW energy, we computed the phase average of $K E$ (Figure 6C). The phase and depth averaged $K E$ in Figure 6C1 clearly show that IW energy oscillates in sync with the tidal phase and that the IW energy is approximately twice as large during HW than LW at M6 (Figure 6C1). This appears to be consistent with study results by Richards et al. (2013), who reported the IW energy to be twice as high during HW than during LW at depths similar to this study $(\sim 23 \mathrm{~m})$. However, in contrast to both results, a clear phase lag was observed at M3, and during HW the energy was $65 \%$ of that observed during LW (Figure 6C2). To compute the phase lag, we compared the time at which the $K E$ peaked (on wave arrival) at M3 and M6. At M6, KE peaked at a tidal phase of $1.1 \mathrm{~h}$, while at $\mathrm{M} 3, K E$ peaked at $4.2 \mathrm{~h}$, suggesting a lag of $3.1 \mathrm{~h}$. The $3.1 \mathrm{~h}$ phase lag, and a distance of $3350 \mathrm{~m}$ between M6 and M3, suggests an IW propagation speed of $0.30 \mathrm{~m} / \mathrm{s}$ for the 12-day period. It appears from the above results that once these IWs are generated, they start to drift out of the surface tide phase as they propagate landward. These observations are consistent with those demonstrated by Shroyer et al. (2011),Ponte and Klein (2015), and Buijsman et al. (2017) for tidally forced IWs on continental shelves of the global oceans.

\subsubsection{Thermal Structure}

The lowest measured water temperature during the 12-day study period was $32.19^{\circ} \mathrm{C}$ at $\mathrm{M} 6$ near the seabed in the afternoon of 15 July, 2017. Correspondingly, the air temperature on 15 July was the coolest $\left(33^{\circ} \mathrm{C}\right)$ during the study period, which may explain the relatively low water temperatures on that day. When air temperature and SST were at a minimum, the change of temperature with depth was the largest at all locations, with a maximum surface to bottom difference of $-1.33^{\circ} \mathrm{C}$ recorded at $\mathrm{M} 3$ and a minimum difference of $-0.99^{\circ} \mathrm{C}$ recorded at M6. The highest water temperature $\left(34.57^{\circ} \mathrm{C}\right)$ was recorded at $\mathrm{M} 3$ near the sea surface in the afternoon of 25 July. Overall, the daily average water temperature increased over the study period. The largest increase $\left(1.26^{\circ} \mathrm{C}\right.$, from 31.47 to $\left.32.73^{\circ} \mathrm{C}\right)$ was observed at $\mathrm{M} 3$, and the smallest at $\mathrm{M} 6\left(1.02^{\circ} \mathrm{C}\right.$, from 32.72 to $\left.33.74^{\circ} \mathrm{C}\right)$.

\subsubsection{Thermal Structure and IWs Activity}

Visual examination of the thermal structure at M6 to M3 (Figure 7) reveals IW activity with significant semidiurnal 


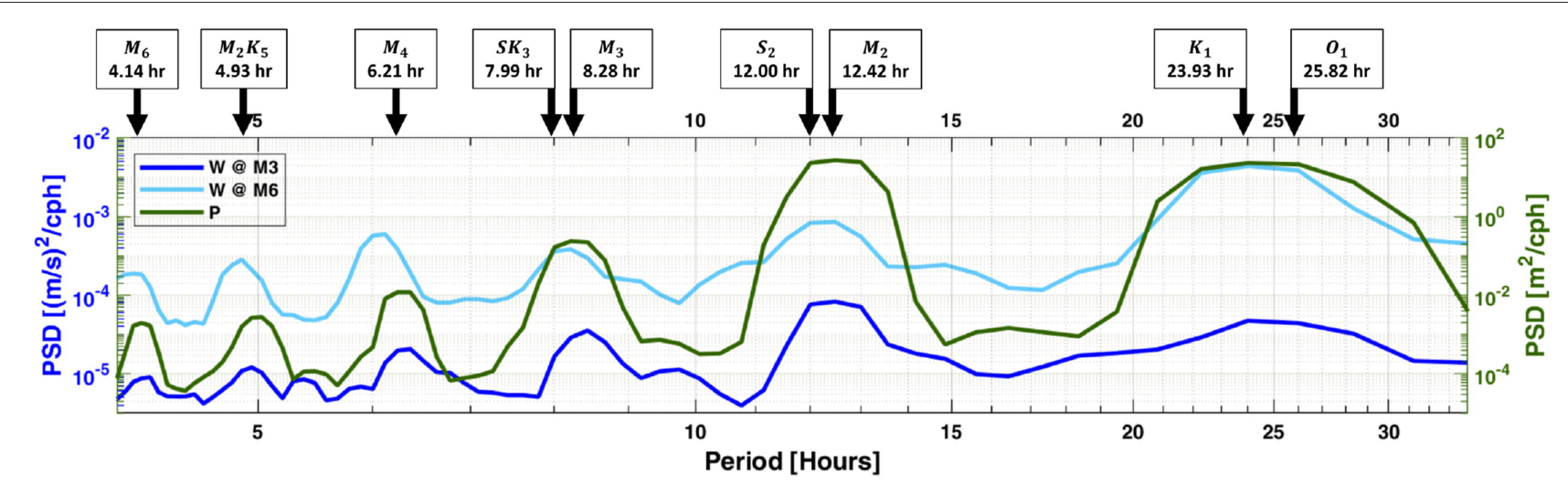

FIGURE 5 | PSD of vertical velocities at M6 (light blue) and M3 (dark blue), computed as the average of all vertical cells, and pressure (green) from 15 to 27 July, 2017. Black arrows indicate tidal constituents during periods when pressure spectral levels appear elevated.

A

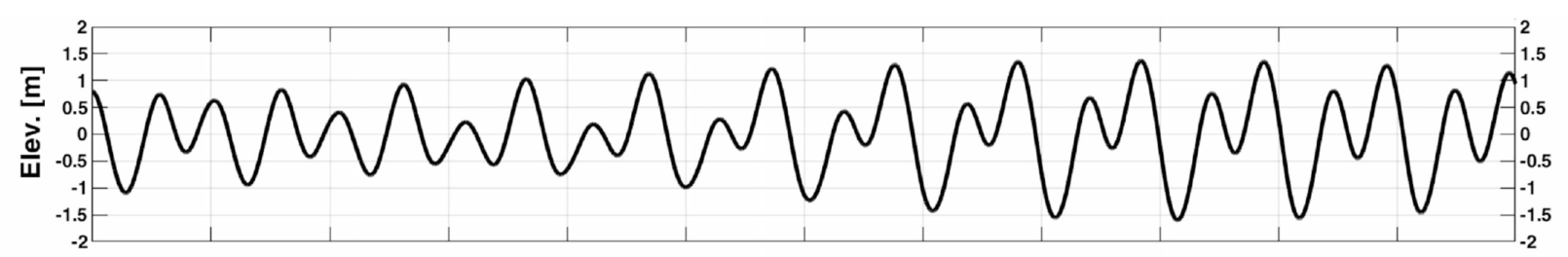

B1

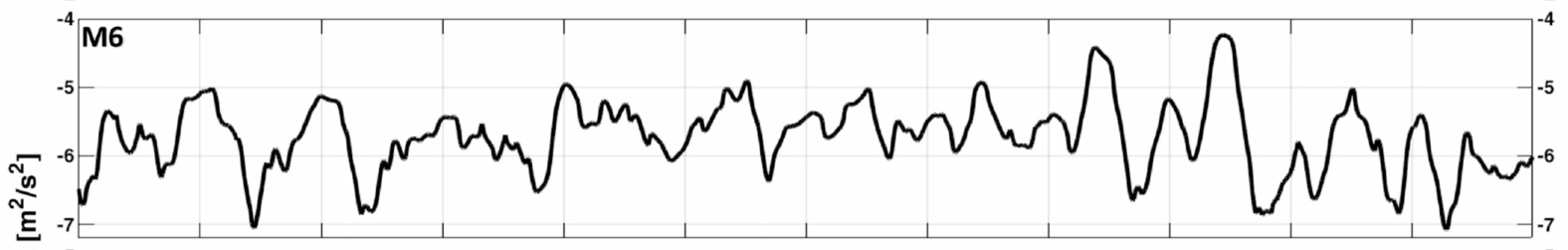

B2

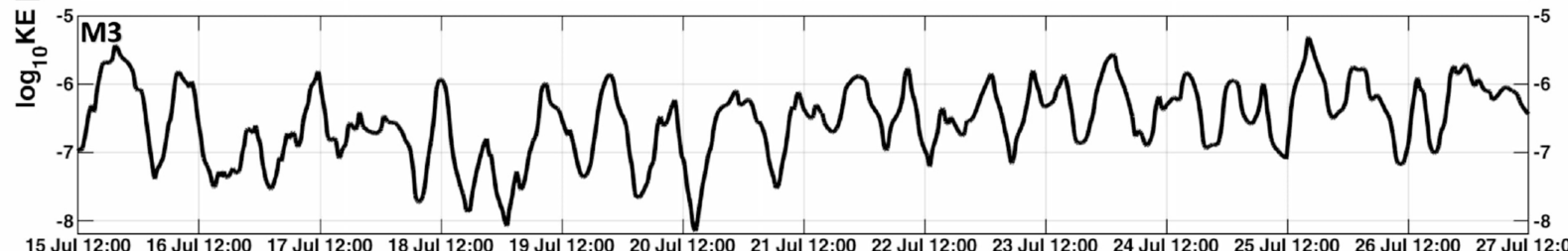

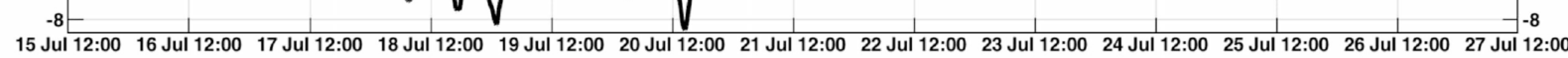

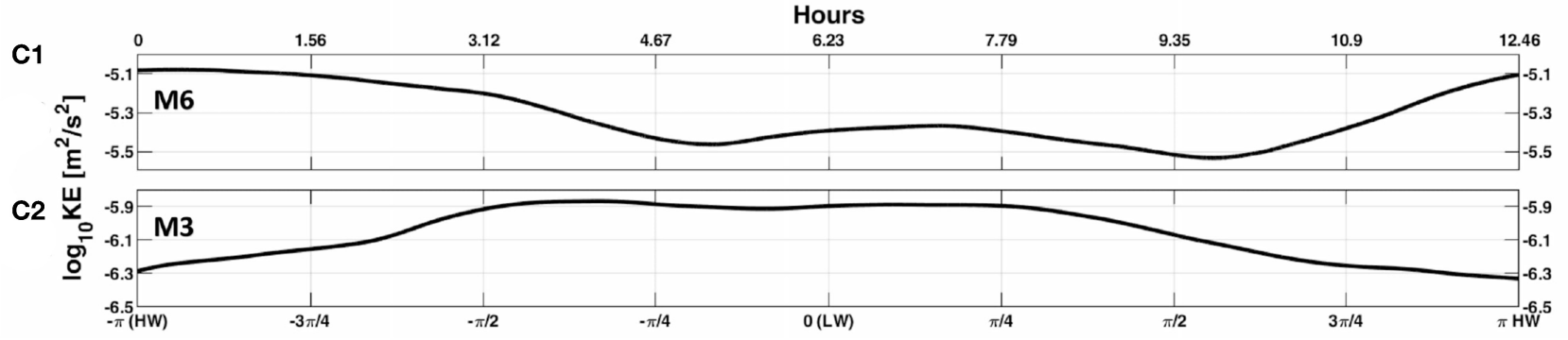

FIGURE 6 | Wave energy at moorings M3 and M6 recorded from 15 to 27 July, 2017. (A) sea surface height variability; (B) KE computed from vertical velocity observations at M6 (B1) and M3 (B2); (C) phase averaged KE at M6 (C1) and M3 (C2). Time in the upper axis of subplot $C$ indicates hours into the M2 surface tide.

oscillations in the thermocline between 15 to 17 July (neap) and 23 to 25 July (spring) (thermocline depth is defined here as the depth where the largest vertical gradient of temperature was observed). This suggests that IWs occur chiefly during neap and spring tides and is different than reported in other studies where IW activity is often absent during neap tides (e.g., Apel,
2002). In contrast, a study by Shroyer et al. (2011) on the New Jersey continental shelf showed that tidally forced IWs during neaps are ten times more energetic with twice the amplitude than during springs. This unpredictable nature of IWs is due to their susceptible to refraction at a given location due to the time varying background low frequency circulation, stratification 


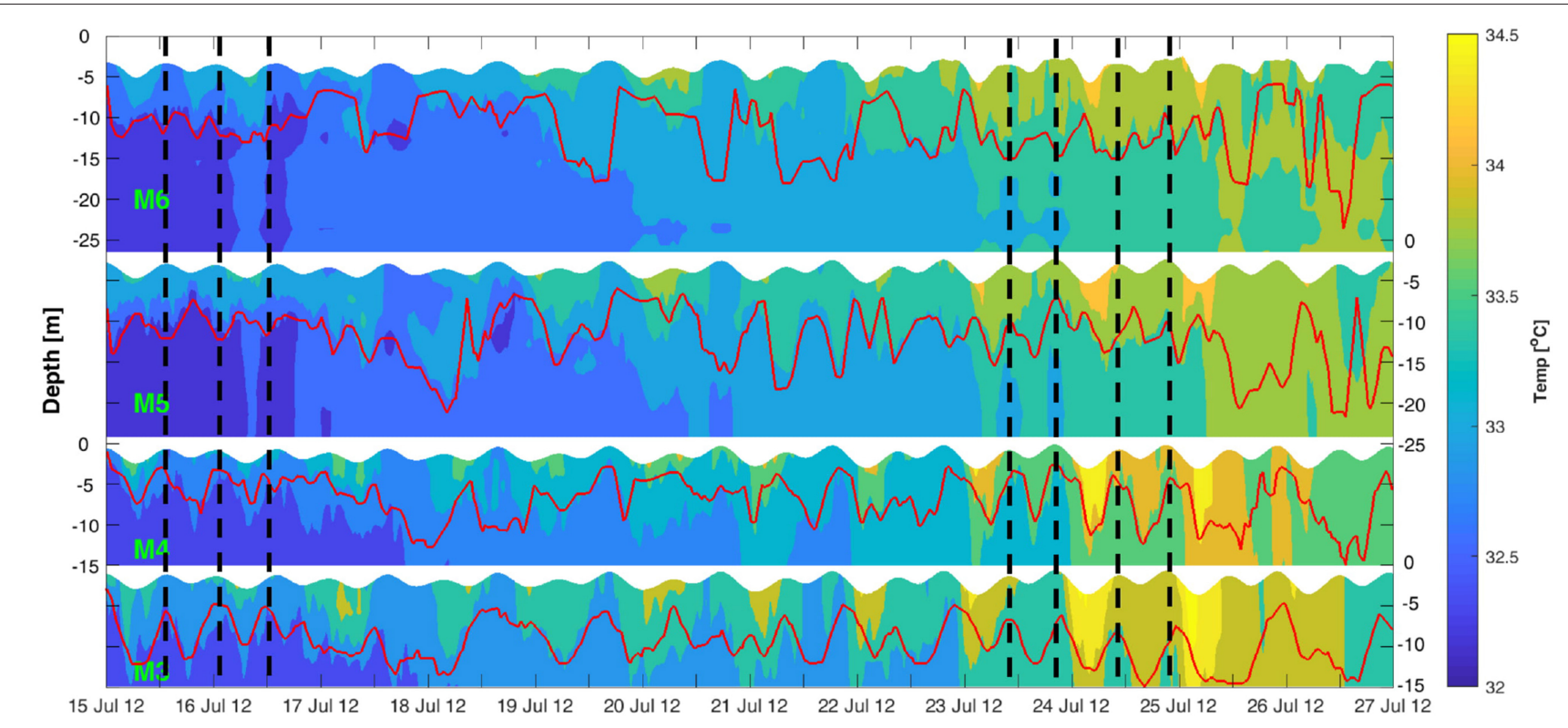

FIGURE 7 | Two hour low-pass filtered thermal structure at the four mooring stations M6 to M3 (top to bottom panels) from 15 to 27 July, 2017. The horizontal red solid line represents the thermocline depth and the vertical black dashed lines indicate periods of HW with noticeable IW activity. Time is UTC.

gradients, relative vorticity all which may force it out of the surface tide phase (Buijsman et al., 2017).

Despite the relatively low $K E$ at M3 compared to that at M6 (Figures 6C1,C2), the undulation seen during the two noticeable periods (15 to 17 and 23 to 25 July) of IW activity reveals larger amplitudes (computed as the changes in thermocline depth) of about $9 \mathrm{~m}$ in the shallower waters at M3 compared to about $6 \mathrm{~m}$ in the deeper waters at M6 (Figure 7). Furthermore, the apparent thermocline oscillation appears to be out of phase at M6 and M5 when compared to that at M4 and M3. This observation is consistent with the phase lag observed in the vertical current velocities and $K E$ between M6 and M3, and may explain the phase lag observed in the thermocline oscillation pattern.

To further analyze the thermal conditions in the thermocline, we focused on the temperature time series measured by the fast-response temperature loggers located in the thermocline at locations M5 and M3 (Figures 8A,B). These stations were selected because they were the nearest (M3) and the farthest (M5) from the shore where fast temperature loggers were available during the two periods of noticeable IW activity.

At M5, where fast temperature loggers $(16 \mathrm{~Hz}$ sampling rate) were deployed, temperature spectrograms and variances were computed in blocks of 65,536 samples $(\sim 68 \mathrm{~min}$; Figure 8A2). Both the spectral and variance levels at mid-depth $(\sim 15 \mathrm{~m})$ roughly follow a semidiurnal cycle. Larger temperature fluctuations during these cycles are clearly observable in the temperature trace as well as in the variances (Figure 8A3). These semidiurnal bursts of elevated spectral and variance levels at middepth follow the vertical oscillation of the thermocline associated with the IW activity. To track the temperature variance changes with depth associated with the oscillation of the thermocline we computed the temperature variances at M5 using eight fast response temperature loggers, in a similar approach as above. Results of this approach are shown in Figure 9, where the depth at which the maximum temperature variance appears (indicated by the horizontal black line) to correlate well with the thermocline oscillation (indicated by the horizontal red line). During the surface tidal flooding phase, the thermocline progressed downward and closer to the temperature loggers located at mid-depth, resulting in elevated spectral and variance levels (Figures 8A, 9). In contrast, during the surface tidal ebbing phase, the thermocline progressed upwards and further away from the temperature loggers located at mid-depth, resulting in lower spectral and variance levels.

Compared to mooring M5, the spectral levels at M3 (sampling rate of $2 \mathrm{~Hz}$, blocks of 8,192 samples, $\sim 68 \mathrm{~min}$ ) were lower during HW (Figures 8B2,B3) but were consistent with M5 by roughly following the semidiurnal cycle. The maximum temperature variance for the four tidal cycles at both locations (indicated by black arrows in Figures 8A3,B3) had a time lag of $1.8 \mathrm{~h}$ between M5 and M3 during the first three tidal cycles. Using the distance of 2,100 m between M5 and M3 this time lag yields an IW speed of $0.31 \mathrm{~m} / \mathrm{s}$ between 15 and 17 July, similar to that computed from the phase lag of the KE between M6 and M3.

\subsection{MicroCTD Observations}

\subsubsection{Location \#1 (15-16 July)}

The first day of turbulence profiling was conducted 550 ! m east of M5 and $741 \mathrm{~m}$ west of M6 (Figure 1) between the afternoons of 15 and 16 July. Winds during the first $5 \mathrm{~h}$ of this period were fair southeasterlies with maximum speeds of $5.7 \mathrm{~m} / \mathrm{s}$. By the end of the profiling period, winds weakened to less than $3.5 \mathrm{~m} / \mathrm{s}$ (Figure 4A). 


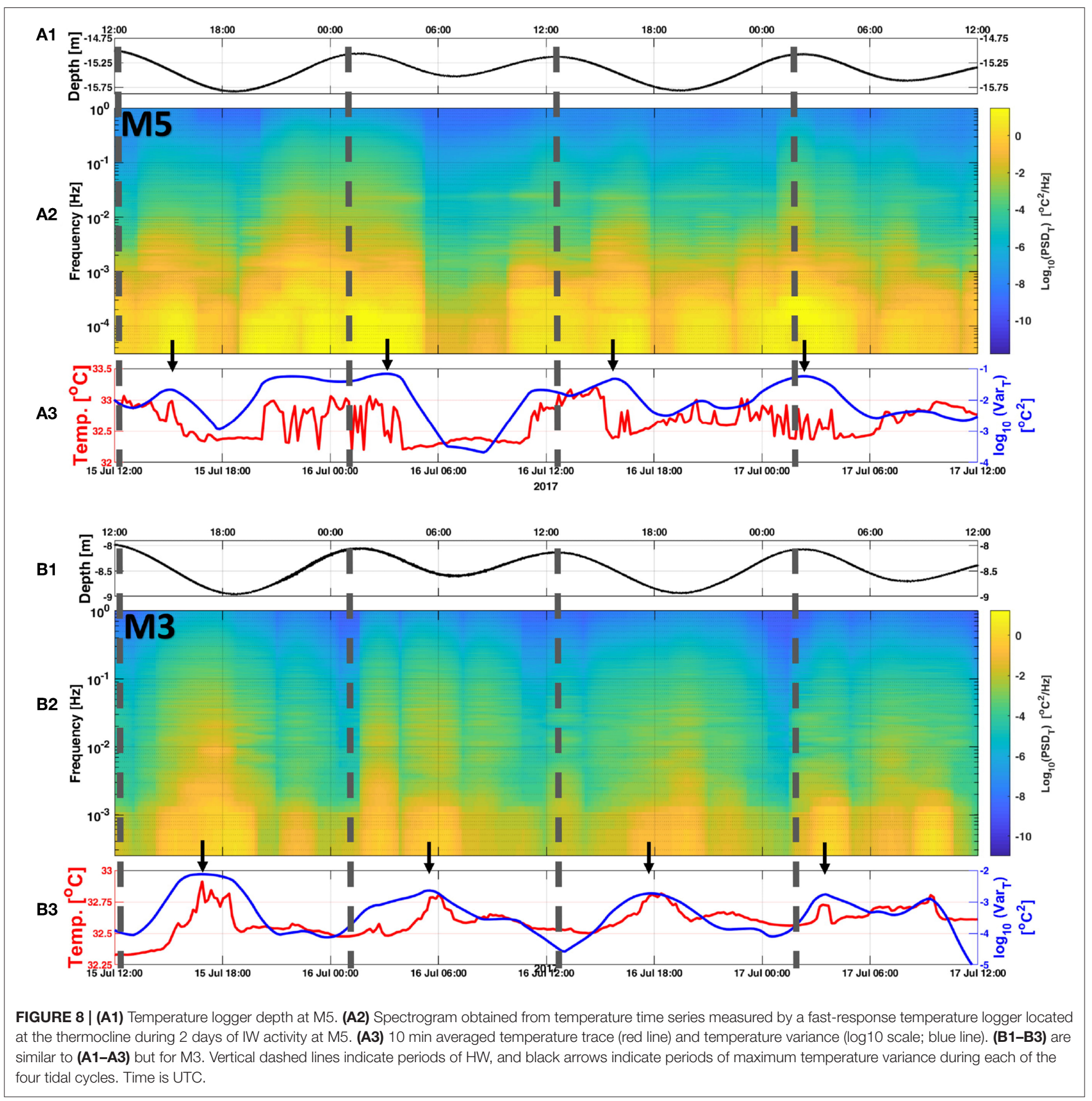

Examination of the thermal structure revealed a general diurnal heating of the upper water column (0-7m) (Figure 10C). Peak daytime solar radiation was $909 \mathrm{~W} / \mathrm{m}^{2}$ with a maximum net surface heat flux of $582 \mathrm{~W} / \mathrm{m}^{2}$ (Figure 10B). Daytime heating was confined to the upper $\sim 7$ m layer, i.e., above the thermocline, and resulted in lower than the nighttime water density of $1,026 \mathrm{~kg} / \mathrm{m}^{3}$ (Figure 10E). Visual inspection of the thermocline (Figure 10C), halocline (Figure 10D), and pycnocline layers (Figure 10E) reveals a clear semidiurnal pattern with the layers being located deeper $(\sim 14.7 \mathrm{~m})$ during HW than during LW $(\sim 7.1 \mathrm{~m})$. This is further emphasized in the one day waterfall plot in Figure 11, where the density profiles clearly show a two layer system divided by a pycnocline(albeit relatively weak) which oscillates in-phase with the tide. It is worth noting that the vertical advection of chlorophyll $a$, being in sync with the vertical movement of the pycnocline, forced the depth of maximum chlorophyll $a$ concentration to decrease during LW and increase during HW (Figure 10C; yellow dots). The advection of chlorophyll $a$ to upper water layers during LW may have contributed to the lower mid-depth DO concentrations (not shown), similar to results 


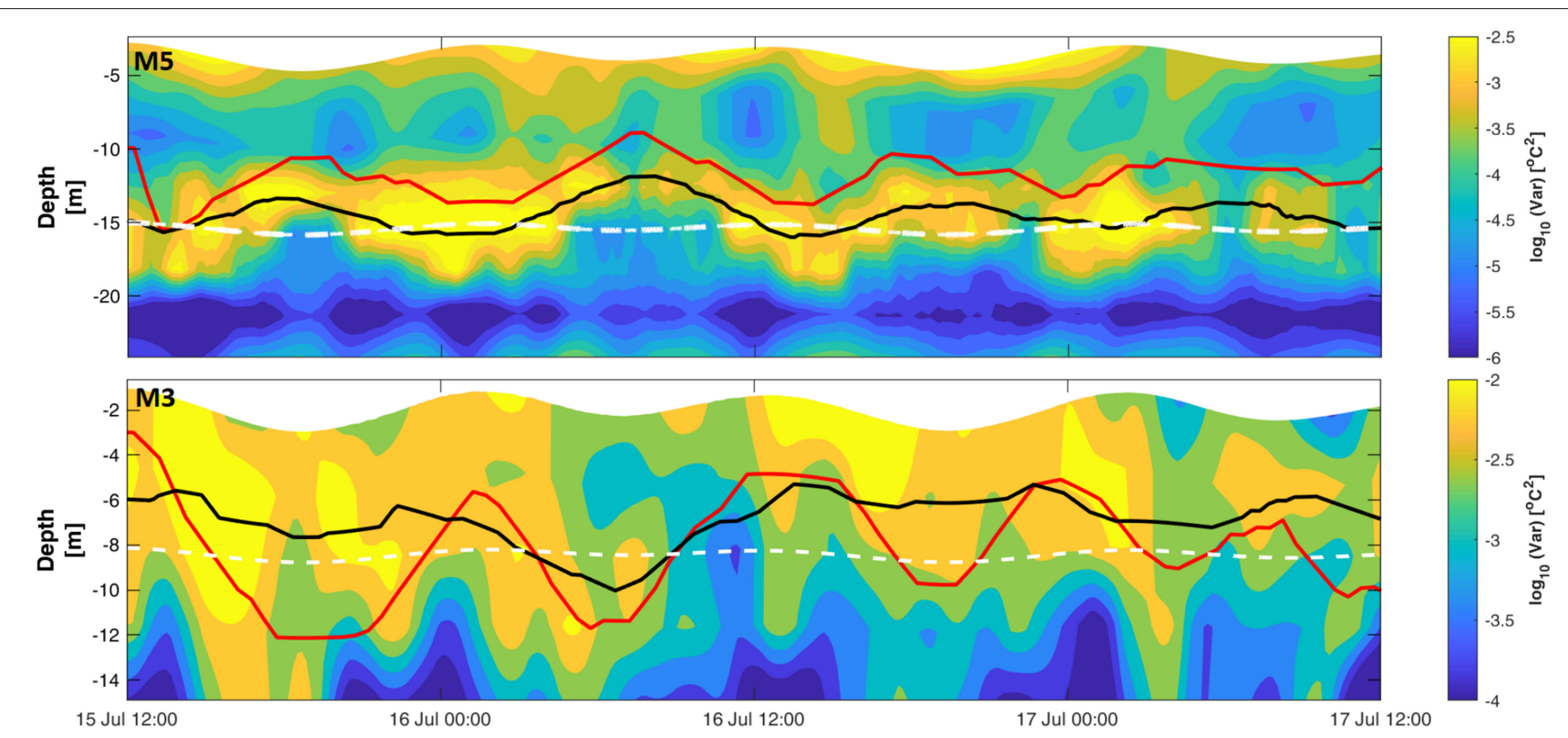

FIGURE 9 | Temperature variance (log10 scale) computed from the temperature loggers at M5 (Top) and M3 (Bottom). Horizontal black and red lines indicate the depths of maximum temperature variance and thermocline, respectively. The white dashed lines indicate the depth of the temperature logger in Figure $\mathbf{8}$. Time is UTC.

reported previously by Wang et al. (2007). The effect of vertical advection is further emphasized by the vertical transport of turbid waters near the bed upward from 14 to $8 \mathrm{~m}$ depth during the ebbing phase and downward from 8 to $14 \mathrm{~m}$ depth during the flooding phase (Figure 10D).

Stability in the upper layer was primarily influenced by surface forcings ( $\tau$ and $J_{q}^{o}$ ) and IW activity. Daytime heating in the upper layer yielded higher buoyancy frequencies than during nighttime (Figure 12B). However, the enhanced buoyancy frequency in the upper layer on the afternoon of 15 July appeared insufficient to maintain a stable upper layer $(\mathrm{Ri}>0.25$; Figure $12 \mathrm{C})$ in contrast to the following afternoon of 16 July. This was likely a result of the higher wind stress on the afternoon of 15 July (up to 0.05 $\mathrm{N} / \mathrm{m}^{2}$; Figure 10A) generating increased vertical shear levels in the upper layer (Figure 12A) and reducing $\mathrm{Ri}$ values $(\mathrm{Ri}<0.25$; Figure 12C), leading to unstable conditions. The instability in the upper layer during the afternoon of 15 July corresponds to higher turbulence levels, as indicated by the larger values of $\epsilon\left(\sim 10^{-5}\right.$ $\mathrm{W} / \mathrm{kg}$ ). Between early morning (4:30) and afternoon of 16 July, lower values of $\epsilon\left(\sim 10^{-8} \mathrm{~W} / \mathrm{kg}\right)$ were observed (Figure 12D).

The highest stability was observed in the thermocline region with buoyancy frequencies exceeding $10^{-4} 1 / \mathrm{s}^{2}$, larger $\mathrm{Ri}$ ( $>0.25$ ), and reduced values of $\epsilon$ (Figures 12B-D). The layer beneath the thermocline, defined here loosely as the bottom boundary layer (BBL) was subject to bursts of enhanced shear instabilities $\left(\geq 0.11 / \mathrm{s}^{2}\right)$ occurring during both flood and ebb cycles, with the lowest values of shear $\left(<0.11 / \mathrm{s}^{2}\right)$ observed during tidal slack. These shear instabilities resulted in lower Ri $(\mathrm{Ri}<0.25)$ and $\epsilon$ values higher than $10^{-7} \mathrm{~W} / \mathrm{kg}$ (Figures 12C,D). We note that shear during the two flood phases was $\sim 30 \%$ lower than during the two ebb phases, and appears to be consistent with the increase in horizontal current speed during ebb. The role of tidally forced IW's in producing near bottom intensified shear, $\epsilon$, and turbidity values compared to other parts of the water column has been reported also by other studies (e.g., Richards et al., 2013). The latter study analyzed semidiurnal internal tides at Ile aux Lievres island, Canada, observing $\epsilon$ values up to $10^{-4} \mathrm{~W} / \mathrm{kg}$ and shear values up to $0.151 / \mathrm{s}^{2}$ in the BBL during the ebbing phase, double the water column average.

In order to examine the generation of IWs at the diurnal and semi-diurnal frequencies, we next investigate the variation in the magnitude and vertical structure of these waves using vertical mode theory (Phillips, 1977; Gill, 1982). Assuming a flat seabed, the vertical structure of these modes can be derived using the buoyancy frequency computed from the microCTD density profiles collected at location \#1,

$$
\frac{\partial}{\partial z}\left(\frac{1}{N^{2}-\omega^{2}} \frac{\partial \psi_{i}}{\partial z}\right)+\frac{1}{c_{i}^{2}} \psi_{i}=0
$$

This approach determines the eigen speed, $c_{i}$, and the vertical isopycnal displacement $\psi_{i}$, of the $i$ th $(i=1-3)$ mode assuming homogeneous boundary conditions such that $\psi(0)=\psi(\mathrm{H})=0$, where $H$ is the water depth (Kelly et al., 2013). The modes were computed using the IWs frequency, $\omega$, of both semi-diurnal $\left(S_{2}\right.$ 12 and $M_{2} 12.42 \mathrm{~h}$ ) tides and both diurnal $\left(\begin{array}{ll}K_{1} & 23.93 \text { and } O_{1}\end{array}\right.$ $25.82 \mathrm{~h}$ ) tidal periods. Using this approach and the dispersion relation, the theoretical group, $c_{g}$, and phase speeds, $c_{p}$, were for the four tidal frequencies computed

$$
\begin{aligned}
c_{g} & =\frac{\left(\omega^{2}-f_{c}^{2}\right)^{1 / 2}}{\omega} c_{i}, \\
c_{p} & =\frac{\omega}{\left(\omega^{2}-f_{c}^{2}\right)^{1 / 2}} c_{i} .
\end{aligned}
$$




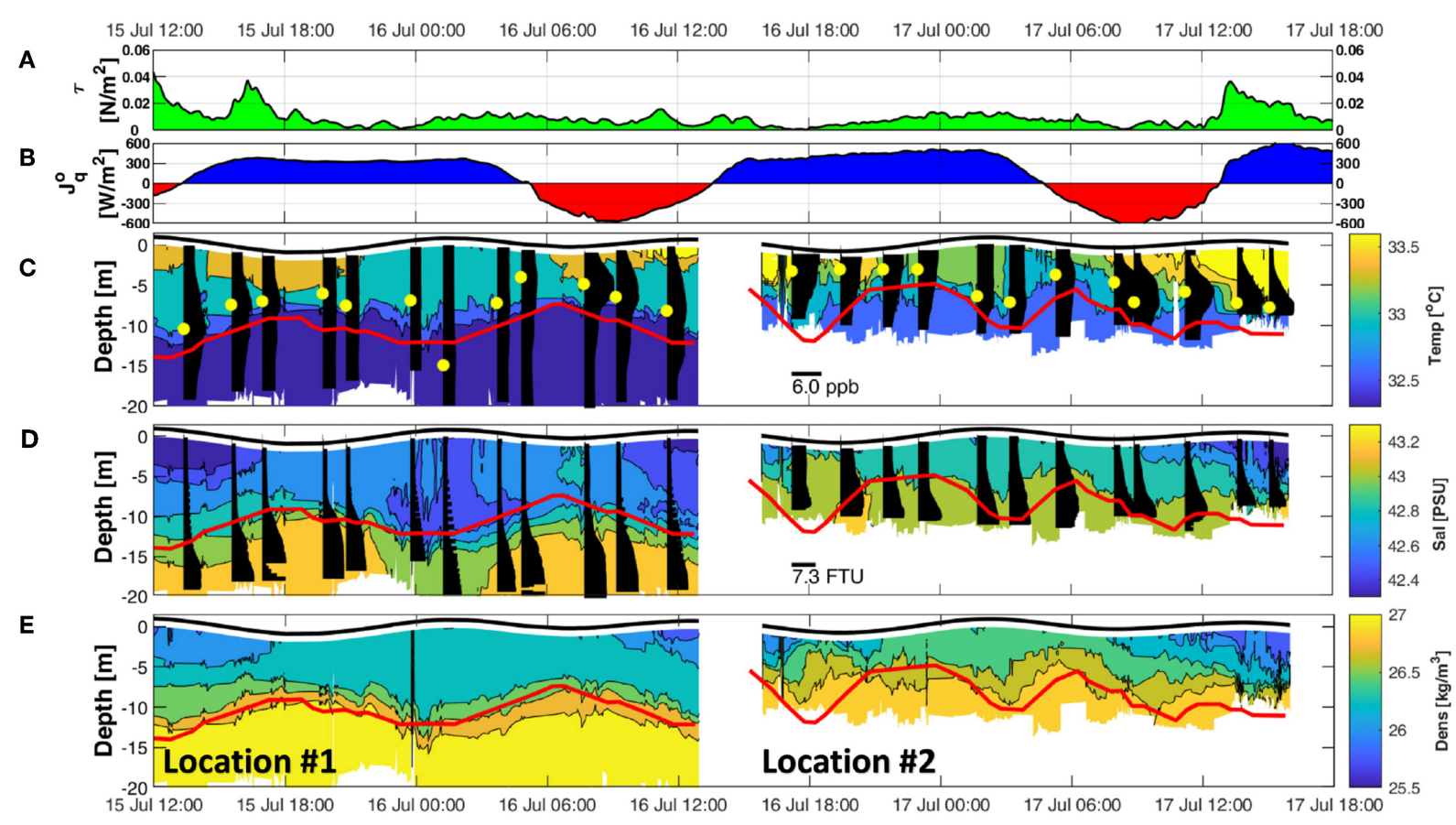

FIGURE 10 | Meteorological and microCTD's hydrography measurements at locations \#1 and \#2. (A) wind stress; (B) net heat flux where negative (red shading) and positive (blue shading) values indicate net heating or cooling, respectively; (C) temperature contours (color) and chlorophyll a concentrations (black bars with maximas indicated by yellow dots; PPB); (D) salinity contours (color) and turbidity (black bars; FTU); (E) density contours (color). Solid red lines in (C-E) indicate the thermocline depth estimated using the temperature loggers at M3 and M6. Time is UTC.

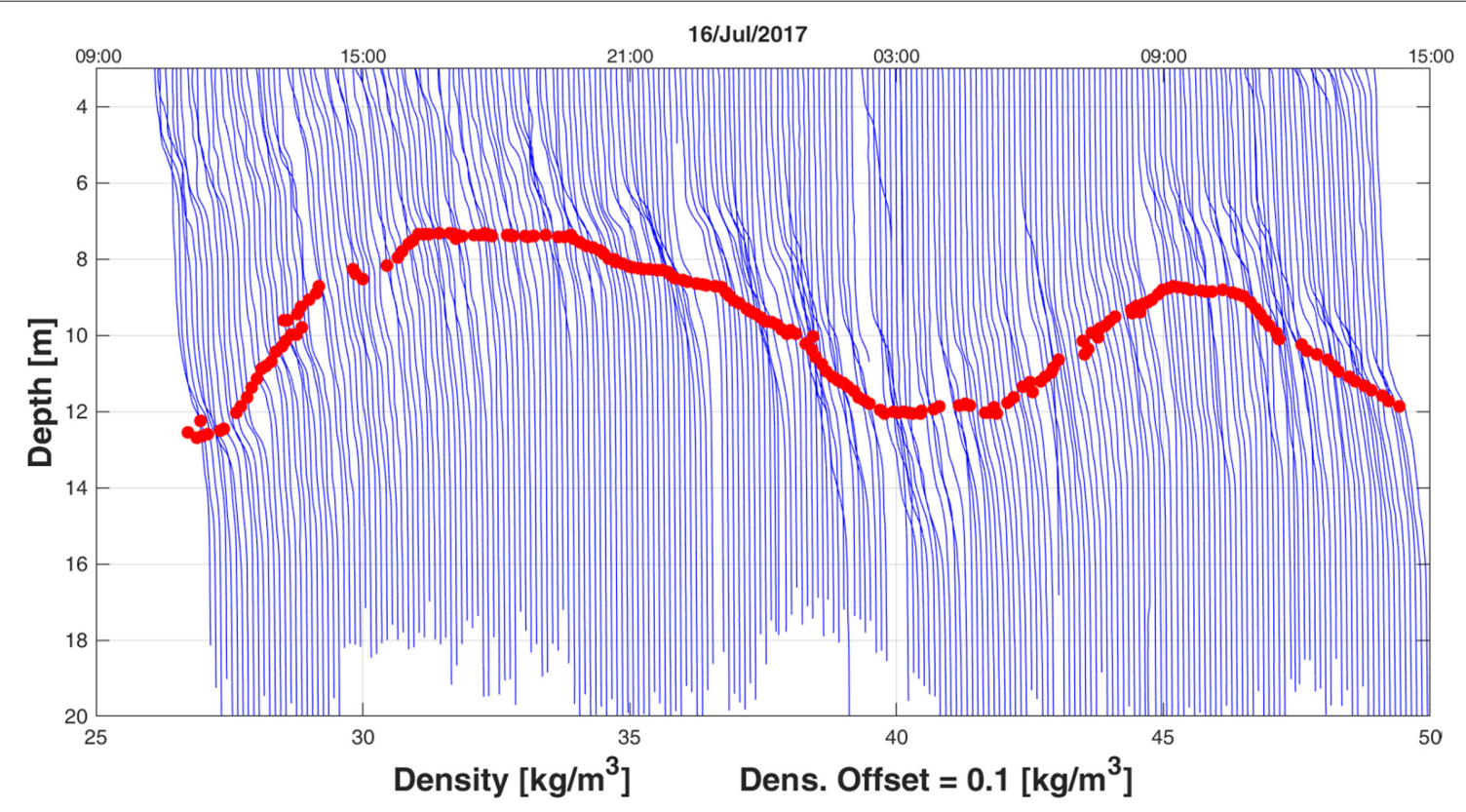

FIGURE 11 | Waterfall plot of density computed from the microCTD profiles at location \#1. The red circles mark the pycnocline depth.

where $f_{c}$ is the Coriolis frequency at our mooring's latitude $29^{\circ} 10^{\prime}$ (Rainville and Pinkel, 2006).

This method is widely used to analyze the variations in dynamical modes associated with IW propagation e.g.,
MacKinnon and Gregg (2003) on the New England Shelf, Ross et al. (2014) in the Fjords of Chile, Stephenson et al. (2015) on the Celtic Sea Shelf, and by Zhang et al. (2016) on the Iberian Continental Margin. Results of the vertical 


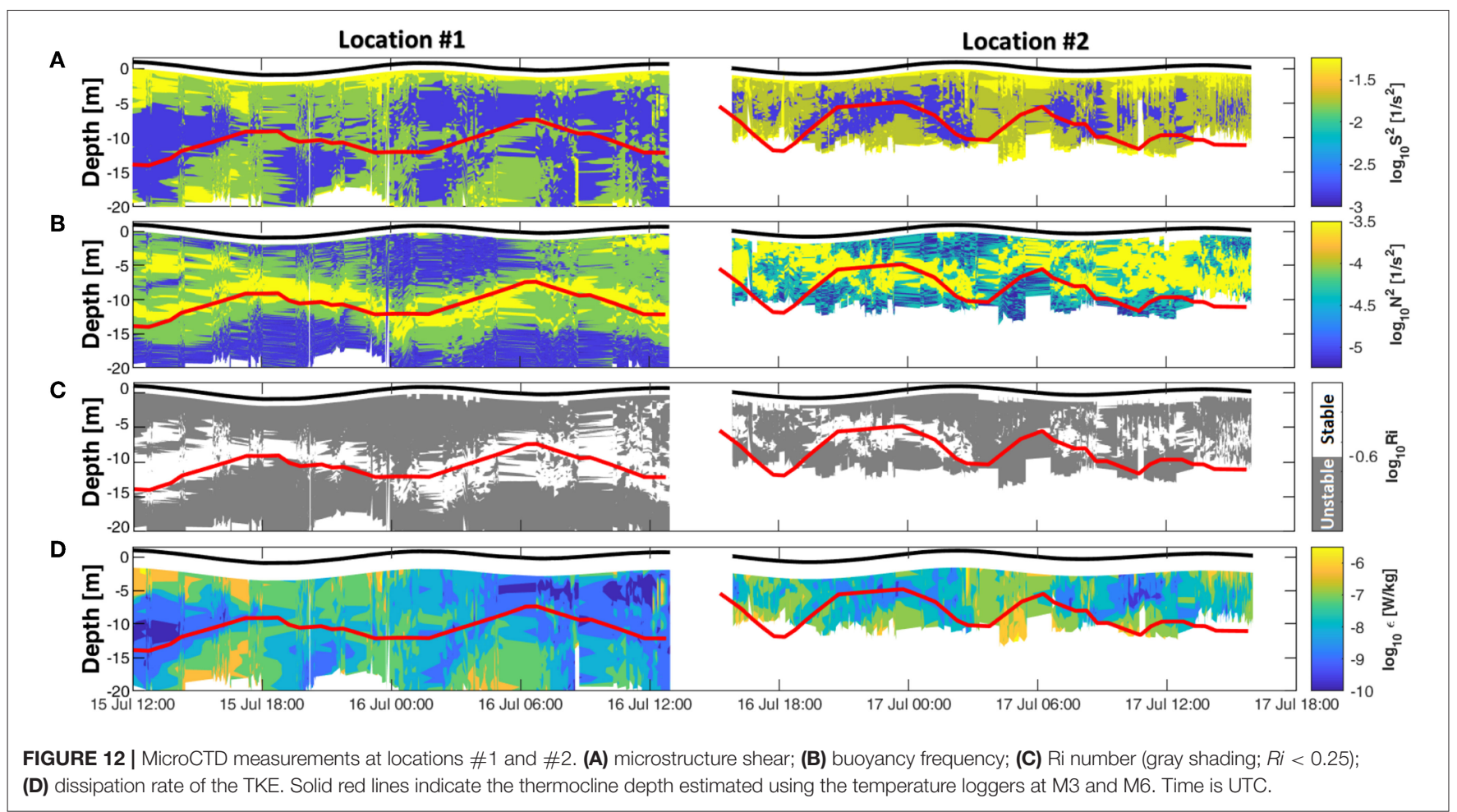

structure of modes 1-3 are presented in Figure 13. The largest values of the buoyancy frequency were found at the pycnocline depth $(9 \mathrm{~m})$ (Figure 13A). The vertical displacement, based on the depth and stratification conditions observed at location $\# 1$, indicate that both diurnal and semi-diurnal (solid black; Figures 13B,C) closely responded to the first mode than to the second mode. The vertical displacement structures for mode- 3 were close to zero. Mode- 1 for both semi-diurnal and diurnal IWs peaked at the pycnocline depth, while mode2 peaked at depths 6 and $13 \mathrm{~m}$. Moreover, both modes1 and 2 vertical displacement during semi-diurnal IWs were about twice in magnitude compared to those of the diurnal IWs. Thus, the existence of the diurnal and semi-diurnal IWs described using the above approach appears to be consistent with the previous results described in section 3.2.2. In addition, the theoretical semi diurnal $\left(S_{2}\right.$ and $\left.M_{2}\right)$ mode-1 IW average phase and group speeds were 0.46 and $0.36 \mathrm{~m} / \mathrm{s}$, respectively. While the diurnal $K_{1}$ mode-1 IW average phase and group speeds were 3.31 and $0.09 \mathrm{~m} / \mathrm{s}$. However, both theoretical phase and group speeds for the $O_{1}$ tidal constituents were near infinity and zero, respectively, ruling out the possibility of $O_{1}$ frequency IW's despite the elevated pressure and vertical velocity spectral levels observed in Figure 5. Further analysis of these elevated spectral levels at the $O_{1}$ frequency will be presented in future work.

\subsubsection{Location \#2 (16 - 17 July)}

The second day of profiling was conducted $122 \mathrm{~m}$ east of M2 and $410 \mathrm{~m}$ west of M3 (Figure 1) from 16:00 on 16 July to $17: 00$ on 17 July. Wind stress during this period was low $\left(<0.01 \mathrm{~N} / \mathrm{m}^{2}\right)$ until the last $3 \mathrm{~h}$ when northwesterly winds strengthened to a speed of $5.9 \mathrm{~m} / \mathrm{s}$, doubling the wind stress to $0.02 \mathrm{~N} / \mathrm{m}^{2}$ (Figure 10A). As described in section 3.1, the maximum air temperature was $49.1^{\circ} \mathrm{C}$ with a maximum drop in day-to-night temperature of $11.1^{\circ} \mathrm{C}$. Furthermore, during this period, the humidity was about half that during the previous day (Figure 10D), resulting in surface heat flux loss larger by $\sim 30 \%$ compared to the previous night (Figure 10B). Similar to location \#1, daytime heating caused the layer above the thermocline to warm by an average $0.6^{\circ} \mathrm{C}$ (Figure 10C) and its buoyancy frequency to triple (Figure 12B).

Unlike location \#1, the combination of large day-tonight temperature drop, low humidity, and high net surface cooling produced by the northwesterly winds at location \#2 induced favorable free convection conditions. This is indicated by near-zero Monin-Obukhov length scales and higher buoyancy losses of up to $2.5 \times 10^{-7} \mathrm{~W} / \mathrm{kg}$, i.e., more than double the maximum observed during profiling at location \#1 (Figures 14A,B).

To further examine these convection conditions, we focus on the $3 \mathrm{~h}$ of high surface buoyancy losses of $>2 \times$ $10^{-7} \mathrm{~W} / \mathrm{kg}$ that occurred between 13:00 and 16:00 17 July. These high buoyancy losses coincided with increase in wind speed, maximum recorded air temperature and SST drop (Figure 4) likely responsible for the convective conditions (Figure 14A). The layer between the surface and thermocline was unstable $(\mathrm{Ri}<0.25$; Figure 12C) during these hours leading to an average $\epsilon$ value of $1.2 \times 10^{-7} \mathrm{~W} / \mathrm{kg}$, about an order of magnitude higher compared to the average value of 

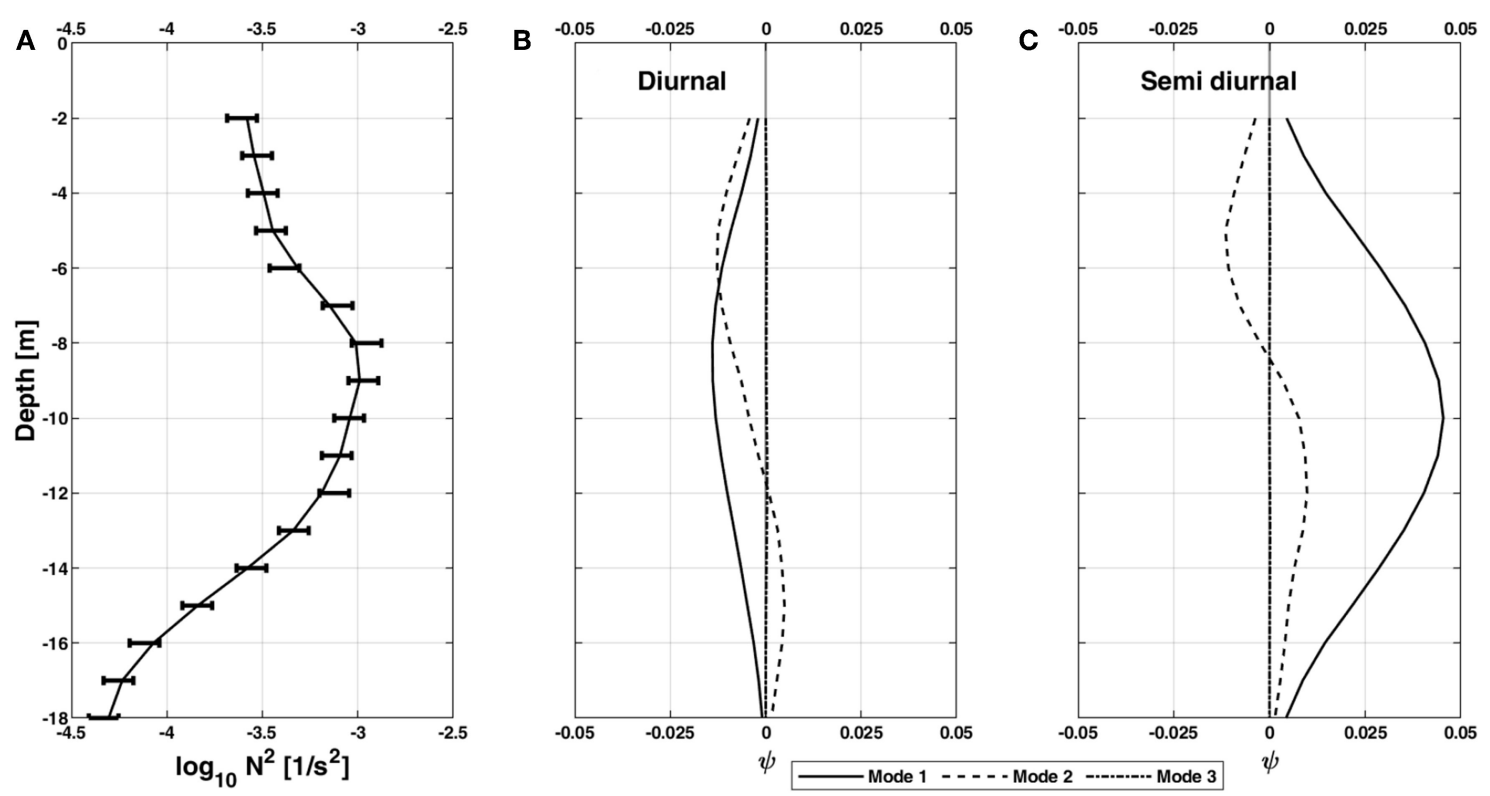

FIGURE 13 | (A) Buoyancy frequency squared profile averaged over location \#1 profiling period; and the normalized vertical displacement mode structures (modes 1 to 3) for the (B) diurnal $K 1$ tide frequency and (C) semi-diurnal (averaged between $S_{2}$ and $M_{2}$ tides) tide frequency.

$1.1 \times 10^{-8} \mathrm{~W} / \mathrm{kg}$ observed $3 \mathrm{~h}$ prior to this period. However, they were not as high as the $\epsilon$ values of $10^{-6} \mathrm{~W} / \mathrm{kg}$ observed near the bottom between 3:00 and 5:00 17 July when the BBL current speed and shear intensity reached their maximal values (Figure 15).

To assess the role of surface buoyancy flux and wind stress to the TKE dissipation rate during these unstable, convective conditions, we examined their contribution to TKE production. This is similar to the idea behind the parameterization suggested first by Shay and Gregg (1986) and Lombardo and Gregg (1989). Here, in the upper layer, the ratio $\left(\frac{\epsilon(z)}{J_{b}^{o}}\right)$ was found to be 0.70 , which is roughly double the second peak ratio of 0.42 observed at 6:00 17 July and higher compared to the period average of 0.16 . This ratio is also consistent with those obtained by Anis and Moum (1992) for night convection in the open ocean, where it is in the range of 0.69 to 0.87 (Figure 14C). Our results are also similar to those of Shay and Gregg (1986) Bahama's experiment of 0.61 to 0.72 , but are higher compared to Lombardo and Gregg (1989) observations of 0.45 to 0.65 . The ratio for production of TKE by wind stress, $\left(\frac{\epsilon(z)}{u_{*}^{3} / \kappa z}\right)$, was found to be $0.20( \pm 0.05)$, despite an increase in wind stress from 0.01 to $0.04 \mathrm{~N} / \mathrm{m}^{2}$. These ratios indicate the clear role of convection in producing the observed instability and deepening of the mixed layer (Figure 12D).

Noticeable IW activity, observed between 15 and 17 July (section 3.2.4), resulted in the thermocline undulating in sync with the semidiurnal tidal phase (Figure 7) at both M3 and location \#1. The thermocline following of the semidiurnal cycle at M3 was also consistent with the observed upward mean velocity during flood and downward during ebb. As expected from the results at M3 and location \#1, the thermocline at location \#2 followed the tidal cycle, moving downward during the ebb period and upward during flood between depths of 5 and $12 \mathrm{~m}$. However, toward the last tidal cycle between 9:00 and 16:00 on 17 July, the thermocline deepened to undulate between 10 and $15 \mathrm{~m}$ depth (Figure 10C). This may be explained by the daytime heating on 17 July which produced the largest net heating of $617 \mathrm{~W} / \mathrm{m}^{2}$ (Figure 10B), commensurate with the highest recorded air temperature of $49.1^{\circ} \mathrm{C}$ and low humidity of $<25 \%$. The maximum buoyancy frequency $\left(0.0011 / \mathrm{s}^{2}\right)$ and $\mathrm{Ri}$ values $>0.25$ (Figures 12B,C) in the layer above the thermocline, observed between 9:00 to 12:00 17 July, may have in turn confined the thermocline to oscillate deeper, between 10 and $15 \mathrm{~m}$ depths. These surface stratified conditions suppressed mixing resulting in the lowest $\epsilon$ values $\left(<10^{-9} \mathrm{~W} / \mathrm{kg}\right)$ recorded during this study. Later, between 13:00 and 16:00 17 July, the upper layer deepened and stratification weakened $(\mathrm{Ri}<0.25)$ due to convection, pushing the thermocline oscillation deeper.

As observed at location \#1, the BBL was subjected to bursts of enhanced shear instabilities $\left(\geq 0.11 / \mathrm{s}^{2}\right)$ during both the flood and ebb cycles, with the smallest values $\left(<0.11 / \mathrm{s}^{2}\right)$ occurring during slack periods (Figure 12A). Shear instabilities during both ebb and flood resulted in Ri values $<0.25$ and $\epsilon$ values $>10^{-7}$ W/kg (Figures 12C,D), similar to those observed at location \#1. To further understand the BBL dynamics, we analyzed the ADV measurements at M2, which provided a detailed picture of the flow conditions $\sim 1.1 \mathrm{~m}$ above the seabed and at a nominal depth of $11.7 \mathrm{~m}$ (Figure 15A). The results show that during slack periods, horizontal current speeds decreased to less than $0.1 \mathrm{~m} / \mathrm{s}$ (Figure 15C), followed by a reduction in the vertical shear to less than $0.0031 / \mathrm{s}^{2}$ (Figure 15D), assuming zero flow at the seabed (Salon et al., 2008). During this tidal slack phase the values of TKE and $\epsilon$ reduced to $<3 \times 10^{-5} \mathrm{~m}^{2} / \mathrm{s}^{2}$ and $<10^{-7}$ $\mathrm{W} / \mathrm{kg}$, respectively (Figures 15E,F). During the weak turbulence conditions, upward vertical velocities decreased to values less than $0.2 \mathrm{~cm} / \mathrm{s}$ (Figure 15B). 

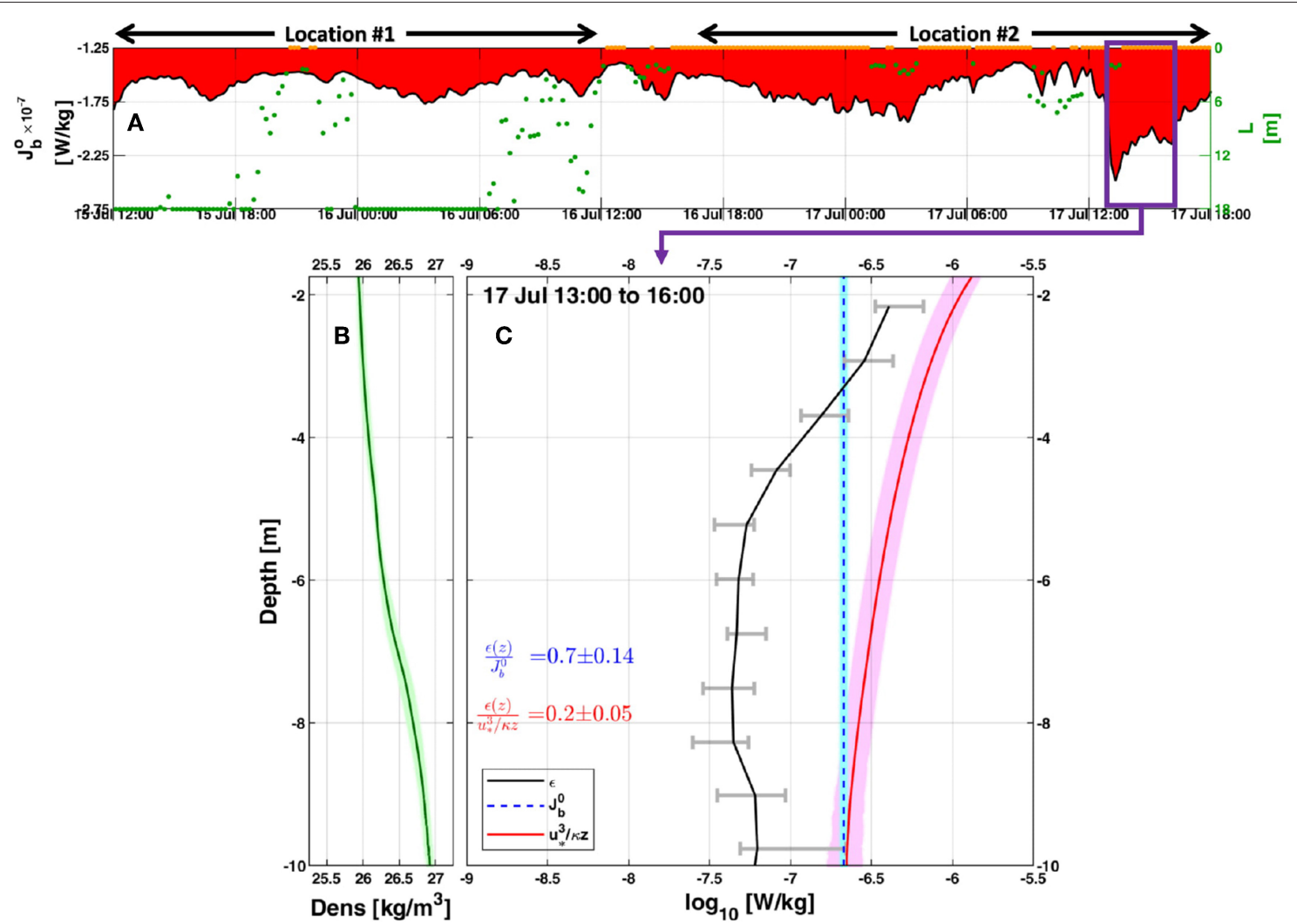

FIGURE 14 | Surface buoyancy flux and MicroCTD measurements at location \#2. (A) Surface buoyancy flux loss in red shading; dots represent the Monin Obukhov length scale to show when turbulence might be dominated by wind stress (green; $L>0$ ) or by convective buoyancy loss at the surface (orange; $L<0$ ). The blue and magenta boxes represent $3 \mathrm{~h}$ periods of pre and during possible convective conditions, respectively; (B) $3 \mathrm{~h}$ averaged density profile (green line) with their $95 \%$ confidence intervals in shading; (C) $3 \mathrm{~h}$ averaged profiles with their $95 \%$ confidence intervals of $\epsilon$ (black line), and production terms of $T K E$ by wind (red line; $u_{*}^{3} / \kappa z$ ) and buoyancy (blue line; $\left.J_{b}^{o}\right)$. Time is UTC.

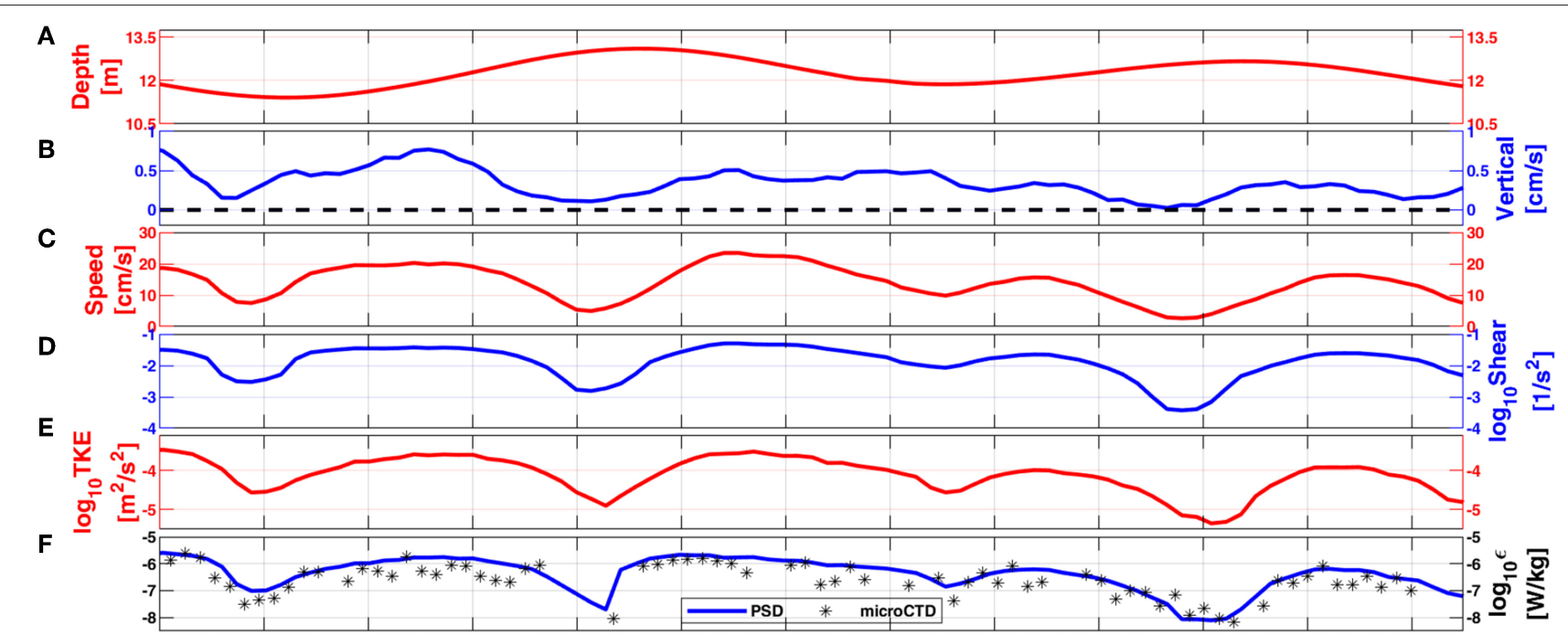

FIGURE 15 | ADV data collected during microstructure profiling at location \#2. (A) water depth; (B) vertical velocity; (C) horizontal current speed; (D) vertical shear of horizontal velocity computed with the assumption that the flow at the seabed is zero; (E) TKE (log10 scale) computed from the vertical velocity; (F) TKE Dissipation rate (log10 scale) estimated from the vertical velocity PSD (blue) and from the microCTD measurements within the BBL (black asterisks). Time is UTC. 
In contrast, during ebb and flood phases, horizontal currents were more than twice in magnitude than during tidal slack, with a maximum speed of $0.26 \mathrm{~m} / \mathrm{s}$. The higher vertical shear $\left(>0.011 / \mathrm{s}^{2}\right)$ was consistent with the faster currents, and resulted in an increase in turbulence as indicated by the relatively high TKE and $\epsilon$ values of $>10^{-4} \mathrm{~m}^{2} / \mathrm{s}^{2}$ and $>10^{-7} \mathrm{~W} / \mathrm{kg}$, respectively. The periods of maximum mixing observed by the ADV at 03:00 on 17 July were consistent with the elevated values of $\epsilon\left(10^{-6} \mathrm{~W} / \mathrm{kg}\right)$ obtained from microCTD profiles at location \#2 during the same time. During these elevated turbulence conditions, the mean upward vertical velocities increased to more than $0.5 \mathrm{~cm} / \mathrm{s}$ (Figure 15B).

For the large Reynold numbers, $\mathrm{Re}=\mathrm{UL}_{n} / \nu$, observed during this experiment $\left(\operatorname{Re} \sim 2 \times 10^{6}\right.$, where we used representative values of $U=0.2 \mathrm{~m} / \mathrm{s}, \mathrm{L}_{n}=10 \mathrm{~m}$, and $v=10^{-6} \mathrm{~m}^{2} / \mathrm{s}$ ) and assuming homogeneous and isotropic turbulence, we expect a well-separated region of wavenumbers lying between that of the energy containing eddies and the dissipative viscous scales (e.g., Tennekes and Lumley, 1972; Pope, 2000). This region is the inertial subrange in which the energy spectrum, $F_{i i}(k)$, is predicted to follow the famous Kolmogorov minus five-thirds law (Equation 1) (Kolmogorov, 1968; Tennekes and Lumley, 1972; Monin and Ozmidov, 1985).

A cornerstone in dissipation scaling of turbulence is $\epsilon \approx$ $U^{3} / 1$, where $U$ and 1 are the velocity and integral length scales, respectively, which characterize the energy-containing turbulent eddies which inject the TKE (e.g., Vassilicos, 2015). To estimate the time scale (frequency) associated with the energycontaining turbulent eddies we estimated their representative velocity scale as $\mathrm{w}^{*} \approx \sqrt{\left(\operatorname{var}\left(w^{\prime}\right)\right)}$, where $w^{\prime}$ is the vertical velocity component measured by the-near bottom mounted $\mathrm{ADV}$. The integral eddy length was assumed as the distance of the ADV's measurement volume above the bottom, i.e., $1.1 \mathrm{~m}$. The resulting average time scale for the energycontaining turbulent eddies, $\mathrm{t} \approx 1 / w^{\prime}$, is $41 \mathrm{~s}$, with a $\max$ of 100 s. It is likely that energy-containing eddies in other parts of the water column may have larger integral and time scales.

To summarize-hydrography and microstructure measurements at locations \#1 and \#2 indicate that IW activity followed a semidiurnal cycle consistent with the observations of vertical velocities, $K E$ (section 3.2.2), and thermal structure (section 3.2.4). Furthermore, similar to location \#1, the maximum chlorophyll $a$ concentration (Figure 10C) generally followed the thermocline vertical undulations spanning a vertical range of about $9 \mathrm{~m}$.

\section{CONCLUSIONS}

This work offers the first detailed study of IW characteristics in the northwestern Gulf off the coast of Kuwait. These waves were detected through their induced changes in temperature, salinity, density, currents, turbidity, chlorophyll $a$, and the resulting turbulence. The vertical velocity data revealed that IW activity closely followed the semidiurnal and diurnal tidal cycles. This was further emphasized by the vertical velocity spectra which clearly indicated elevated spectral levels during four peak periods commensurate with the major tidal constituents $\mathrm{O}_{1}, M_{2}$, and $S_{2}$. Our results appear to be consistent with other studies which indicate the role of semidiurnal tides (e.g., Bourgault and Kelley, 2003; Richards et al., 2013) and the role of multiple tidal constituents (e.g., Colosi et al., 2001; Sun and Pinkel, 2012) in the generation of IWs.

IWs, with amplitudes ranging from 7 to $9 \mathrm{~m}$, were found to propagate toward the shore at an average speed of 0.31 $\mathrm{m} / \mathrm{s}$. Larger amplitude waves were observed closer to the shore. The changes in meteorological conditions associated with the northwesterly and southeasterly winds contributed to variability in the water column stability conditions. At times, IW activity was disrupted and forced to propagate deeper due to enhanced stratification in the surface layer resulting from extreme heating periods during exceptional hot and dry conditions. In addition, surface heat losses coinciding with increase in wind speed, drop in humidity, maximum recorded air temperature, and SST drop associated with the northwesterly winds led to convective conditions which led to instability and deepening of the mixed layer.

At the thermocline depth, the buoyancy frequency was higher and current shear was lower compared to the rest of the water column. This resulted in larger Ri values indicating suppression of mixing intensity in the thermocline. Highest TKE dissipation rates $\left(>10^{-7} \mathrm{~W} / \mathrm{kg}\right.$ ) were observed to occur in bursts in the $\mathrm{BBL}$, following the tidal cycle, and were closely tied to enhanced shear instabilities during both flood and ebb. Shear was lowest during tidal slack. We also note that shear instability during ebb was $\sim 30 \%$ higher than during flood, resulting in more intense mixing beneath the IW's crest. These observations are in agreement with results of Richards et al. (2013) who observed a similar increase in BBL shear (water depth of $23 \mathrm{~m}$ ) following the semidiurnal tidal cycle at Ile aux Lievres island, Canada, during summer.

Future work is planned to explore IW propagation in the far-field, before the IWs encounter the slope and start to breakup, to provide additional spatial and directional information on the undisturbed incoming waves. Further indepth observational studies of wind-forced and thermallydriven convection in the Gulf should also provide new insights on formation of the GDW and its spilling into the Indian Ocean as well as a better understanding of the relation to the circulation in the Arabian sea. Lastly, the detailed physical oceanographic and surface meteorological datasets collected during this study should be useful for testing and improvement of present and future regional numerical circulation models, in particular due to the scarcity of such observations in the Gulf.

\section{DATA AVAILABILITY STATEMENT}

The raw data supporting the conclusions of this article will be made available by the authors, without undue reservation, to any qualified researcher. 


\section{AUTHOR CONTRIBUTIONS}

FA and AA contributed equally in data collection, data analysis, and manuscript preparation.

\section{FUNDING}

This study was funded by the Kuwait Foundation for Advancement of Sciences (project \#P21644SE01).

\section{REFERENCES}

Al Senafi, F., and Anis, A. (2015). Shamals and climate variability in the Northern Arabian/Persian Gulf from 1973 to 2012. Int. J. Climatol. 35, 4509-4528. doi: $10.1002 /$ joc. 4302

Alford, M. (2003). Redistribution of energy available for ocean mixing by long-range propagation of internal waves. Nature 423, 159-162. doi: 10.1038 /nature 01628

Anis, A. (2006). Similarity relationships in the unstable aquatic surface layer. Geophys. Res. Lett. 33:L19609. doi: 10.1029/2006GL027268

Anis, A., and Moum, J. (1992). The superadiabatic surface layer of the ocean during convection. J. Phys. Oceanogr. 22, 1221-1227. doi: 10.1175/1520-0485(1992)022<1221:TSSLOT>2.0.CO;2

Apel, J. R. (2002). "Oceanic internal waves and solitons," in An Atlas of Oceanic Internal Solitary Waves. Global Ocean Associates. Prepared for Office of Naval Research (Code 322 PO), ed C. R. Jackson (Alexandria, VA), 189-206.

Bluteau, C. E., Jones, N. L., and Ivey, G. N. (2016). Estimating turbulent dissipation from microstructure shear measurements using maximum likelihood spectral fitting over the inertial and viscous subranges. J. Atmos. Ocean. Technol. 33, 713-722. doi: 10.1175/JTECH-D-15-0218.1

Bourgault, D., and Kelley, D. E. (2003). Wave-induced boundary mixing in a partially mixed estuary. J. Mar. Res. 61, 553-576. doi: $10.1357 / 002224003771815954$

Buijsman, M. C., Arbic, B. K., Richman, J. G., Shriver, J. F., Wallcraft, A. J., and Zamudio, L. (2017). Semidiurnal internal tide incoherence in the equatorial Pacific. J. Geophys. Res. Oceans 122, 5286-5305. doi: 10.1002/2016JC012590

Carter, G. S., Gregg, M. C., and Lien, R. C. (2005). Internal waves, solitarylike waves, and mixing on the Monterey Bay shelf. Continent. Shelf Res. 25, 1499-1520. doi: 10.1016/j.csr.2005.04.011

Colosi, J. A., Beardsley, R. C., Lynch, J. F., Gawarkiewicz, G., Chiu, C. S., and Scotti, A. (2001). Observations of nonlinear internal waves on the outer New England continental shelf during the summer Shelfbreak Primer study. J. Geophys. Res. C Oceans 106, 9587-9601. doi: 10.1029/2000JC900124

Fairall, C., Bradley, E., Hare, J., Grachev, A., and Edson, J. (2003). Bulk parameterization of air-sea fluxes: updates and verification for the COARE algorithm. J. Clim. 16, 571-591. doi: 10.1175/1520-0442(2003)016<0571:BPOASF $>2.0 . C O ; 2$

Fairall, C., Bradley, E., Rogers, D., Edson, J., and Young, G. (1996). Bulk parameterization of air-sea fluxes for tropical ocean- global atmosphere coupled-ocean atmosphere response experiment difference relative analysis. J. Geophys. Res. 101, 3747-3764. doi: 10.1029/95JC03205

Galperin, B., Sukoriansky, S., and Anderson, P. S. (2007). On the critical Richardson number in stably stratified turbulence. Atmos. Sci. Lett. 8, 65-69. doi: 10.1002/asl.153

Gill, A. E. (1982). Atmosphere-Ocean Dynamics. New York, NY: Academic Pres Inc.,, 662.

Goodman, L., Levine, E. R., and Lueck, R. G. (2006). On measuring the terms of the turbulent kinetic energy budget from an AUV. J. Atmos. Ocean. Technol. 23, 977-990. doi: 10.1175/JTECH1889.1

Islam, M., and Zhu, D. (2013). Kernel density-based algorithm for despiking ADV data. J. Hydraulic Eng. 139, 785-793. doi: 10.1061/(ASCE)HY.1943-7900.0000734

Kelly, S. M., Jones, N. L., and Nash, J. D. (2013). A coupled model for laplace's tidal equations in a fluid with one horizontal dimension and variable depth. J. Phys. Oceanogr. 43, 1780-1797. doi: 10.1175/JPO-D-12-0147.1

\section{ACKNOWLEDGMENTS}

We thank the Kuwaiti Coast Guard for providing field logistics, transportation and divers, and graduate students Mr. Sergey Molodtsov (Texas A\&M University, USA) and Mr. Ahmed Al Rawahi (Sultan Qaboos University, Oman) for assistance in the field. We are also grateful to Mr. Evan Cervelli (Rockland Scientific) for providing technical assistance during the field campaign.

Kelly, S. M., Nash, J. D., and Kunze, E. (2010). Internal-tide energy over topography. J. Geophys. Res. Oceans 115, 1-13. doi: 10.1029/2009JC005618

Khorsandi, B., Mydlarski, L., and Gaskin, S. (2012). Noise in turbulence measurements using acoustic doppler velocimetry. J. Hydraulic Eng. 138, 829838. doi: 10.1061/(ASCE)HY.1943-7900.0000589

Kolmogorov, A. N. (1968). Local structure of turbulence in an incompressible viscous fluid at very high Reynolds numbers. Soviet Phys. Uspekhi 10, 734-746. doi: 10.1070/PU1968v010n06ABEH003710

Kunze, E., MacKay, C., McPhee-Shaw, E. E., Morrice, K., Girton, J. B., and Terker, S. R. (2012). Turbulent mixing and exchange with interior waters on sloping boundaries. J. Phys. Oceanogr. 42, 910-927. doi: 10.1175/JPO-D11-075.1

Lamb, K. G., and Farmer, D. (2011). Instabilities in an internal solitary-like wave on the oregon shelf. J. Phys. Oceanogr. 41, 67-87. doi: 10.1175/2010JPO 4308.1

Laurent, L., Alford, M., and Paluszkiewicz, T. (2012). An introduction to the special issue on internal waves. Oceanography 25, 15-19. doi: 10.5670/oceanog.2012.37

Lombardo, C. P., and Gregg, M. C. (1989). Similarity scaling of viscous and thermal dissipation in a convecting surface boundary layer. J. Geophys. Res. 94, 6273-6284. doi: 10.1029/JC094iC05p06273

MacKinnon, J. A., and Gregg, M. C. (2003). Shear and baroclinic energy flux on the summer new England shelf. J. Phys. Oceanogr. 33, 1462-1475. doi: 10.1175/1520-0485(2003)033<1462:SABEFO >2.0.CO;2

Monin, A. S., and Obukhov, A. M. (1954). Basic laws of turbulent mixing in the surface layer of the atmosphere. Contrib. Geophys. Inst. Acad. Sci. USSR 24, 163-187.

Monin, A. S., and Ozmidov, R. V. (1985). Turbulence in the Ocean. Dordrecht: D. Reidel Pub Corp.S.

Moum, J. N. (1996). Efficiency of mixing in the main thermocline. J. Geophys. Res. Oceans 101, 12177-12191. doi: 10.1029/96JC00508

Moum, J. N., Caldwell, D. R., Nash, J. D., and Gunderson, G. D. (2002). Observations of boundary mixing over the continental slope. J. Phys. Oceanogr. 32, 2113-2130. doi: 10.1175/1520-0485(2002)032<2113:OOBMOT>2.0.CO;2

Moum, J. N., Klymak, J. M., Nash, J. D., Perlin, A., and Smyth, W. D. (2007). Energy transport by nonlinear internal waves. J. Phys. Oceanogr. 37, 1968-1988. doi: $10.1175 / J P O 3094.1$

Nash, J. D., Kelly, S. M., Shroyer, E. L., Moum, J. N., and Duda, T. F. (2012). The unpredictable nature of internal tides on continental shelves. J. Phys. Oceanogr. 42, 1981-2000. doi: 10.1175/JPO-D-12-028.1

Nash, J. D., and Moum, J. N. (2001). Internal hydraulic flows on the continental shelf: High drag states over a small bank. J. Geophys. Res. Oceans 106, 45934611. doi: 10.1029/1999JC000183

Nasmyth, P. (1970). Oceanic Turbulence. Ph.D. thesis, University of British Columbia, Vancouver, BC, Canada.

Nasrallah, H. A., Nieplova, E., and Ramadan, E. (2004). Warm season extreme temperature events in Kuwait. J. Arid Environ. 56, 357-371. doi: 10.1016/S0140-1963(03)00007-7

Nezlin, N., Polikarpov, I., Al-Yamani, F., Subba Rao, D., and Ignatov, A. (2010). Satellite monitoring of climatic factors regulating phytoplankton variability in the Arabian (Persian) Gulf. J. Mar. Syst. 82, 47-60. doi: 10.1016/j.jmarsys.2010.03.003

Oakey, N. (1982). Determination of the rate of dissipation of turbulent energy from simultaneous temperature and velocity shear micro- structure measurements. J. Phys. Oceanogr. 12, 256-271. doi: 10.1175/1520-0485(1982)012<0256:DOTROD >2.0.CO;2 
Osborn, T., and Crawford, W. (1980). An Airfoil Probe for Measuring Turbulent Velocity Fluctuations in Water. Boston, MA: Springer.

Phillips, O. (1977). The Dynamics of the Upper Ocean, 2nd Edn. New York, NY: Cambridge Univ. Press.

Ponte, A. L., and Klein, P. (2015). Incoherent signature of internal tides on sea level in idealized numerical simulations. Geophys. Res. Lett. 42, 1520-1526. doi: 10.1002/2014GL062583

Pope, S. (2000). Turbulent Flows. Cambridge: Cambridge University Press.

Quaresma, L. S., Vitorino, J., Oliveira, A., and da Silva, J. (2007). Evidence of sediment resuspension by nonlinear internal waves on the western Portuguese mid-shelf. Mar. Geol. 246, 123-143. doi: 10.1016/j.margeo.2007.04.019

Rainville, L., and Pinkel, R. (2006). Propagation of low-mode internal waves through the ocean. J. Phys. Oceanogr. 36, 1220-1236. doi: 10.1175/JPO2889.1

Rao, G., Al-Sulaiti, M., and Al-Mulla, A. (2003). Summer shamals over the Arabian Gulf. Weather 58, 471-478. doi: 10.1002/wea.6080581207

Reynolds, M. (1993). Physical oceanography of the Persian Gulf, Strait of Hormuz, and the Gulf of Oman - Results from the Mt. mitchell expedition. Mar. Pollut. Bull. 27, 35-59. doi: 10.1016/0025-326X(93)90007-7

Richards, C., Bourgault, D., Galbraith, P. S., Hay, A., and Kelley, D. E. (2013). Measurements of shoaling internal waves and turbulence in an estuary. $J$. Geophys. Res. Oceans 118, 273-286. doi: 10.1029/2012JC008154

Ross, L., Pérez-Santos, I., Valle-Levinson, A., and Schneider, W. (2014). Semidiurnal internal tides in a Patagonian fjord. Prog. Oceanogr. 129, 19-34. doi: 10.1016/j.pocean.2014.03.006

Rusello, P. (2009). A Practical Primer for Pulse Coherent Instruments (TN-027). Tech. rep., Nortek.

Saddoughi, S., and Veeravalli, S. (1994). Local isotropy in turbulent boundary layers at high Reynolds number. J. Fluid Mech. 268, 333-372. doi: $10.1017 /$ S0022112094001370

Salon, S., Crise, A., and Loon, T. (2008). Dynamics of the bottom boundary layer. Dev. Sedimentol. 60, 83-97. doi: 10.1146/annurev.fluid.34.082701.1 61921

Sandstrom, H., and Oakey, N. S. (1995). Dissipation in internal tides and solitary waves. J. Phys. Oceanogr. 25, 604-614. doi: 10.1175/1520-0485(1995)025<0604:DIITAS >2.0.CO;2

Sato, M., Klymak, J. M., Kunze, E., Dewey, R., and Dower, J. F. (2014). Turbulence and internal waves in Patricia Bay, Saanich Inlet, British Columbia. Continent. Shelf Res. 85, 153-167. doi: 10.1016/j.csr.2014.06.009

Shay, T. J., and Gregg, M. C. (1986). Convectively driven turbulent mixing in the upper ocean. J. Phys. Oceanogr. 16, 1777-1798. doi: 10.1175/1520-0485(1986)016<1777:CDTMIT >2.0.CO;2

Shroyer, E. L., Moum, J. N., and Nash, J. D. (2011). Nonlinear internal waves over New Jersey's continental shelf. J. Geophys. Res. Oceans 116, 1-16. doi: 10.1029/2010JC006332
Simpson, J. H., Crawford, W. R., Rippeth, T. P., Campbell, A. R., and Cheok, J. V. S. (1996). The vertical structure of turbulent dissipation in shelf seas. J. Phys. Oceanogr. 26, 1579-1590. doi: 10.1175/1520-0485(1996)026<1579:TVSOTD >2.0.CO;2

Stephenson, G. R., Hopkins, J. E., Mattias Green, J. A., Inall, M. E., and Palmer, M. R. (2015). Baroclinic energy flux at the continental shelf edge modified by wind-mixing. Geophys. Res. Lett. 42, 1826-1833. doi: 10.1002/2014GL062627

Sun, O. M., and Pinkel, R. (2012). Energy transfer from high-shear, low-frequency internal waves to high-frequency waves near Kaena Ridge, Hawaii. J. Phys. Oceanogr. 42, 1524-1547. doi: 10.1175/JPO-D-11-0117.1

Swift, S. A. and Bower, A. (2003). Formation and circulation of dense water in the Persian/Arabian Gulf. J. Geophys. Res. 108:3004. doi: 10.1029/2002JC001360

Tennekes, H., and Lumley, J. (1972). A First Course in Turbulence. Cambridge, MA: MIT Press.

Trowbridge, J., and Elgar, S. (2001). Turbulence measurements in the surf zone. J. Phys. Oceanogr. 31, 2403-2417. doi: 10.1175/1520-0485(2001)031<2403:TMITSZ>2.0.CO;2

Vassilicos, J. C. (2015). Dissipation in turbulent flows. Annu. Rev. Fluid Mech. 47, 95-114. doi: 10.1146/annurev-fluid-010814-014637

Voulgaris, G., and Trowbridge, J. (1998). Evaluation of the acoustic doppler velocimeter (ADV) for turbulence measurements. J. Atmos. Ocean. Technol. 15, 272-289. doi: 10.1175/1520-0426(1998)015<0272:EOTADV>2.0.CO;2

Wang, Y. H., Dai, C. F., and Chen, Y. Y. (2007). Physical and ecological processes of internal waves on an isolated reef ecosystem in the South China Sea. Geophys. Res. Lett. 34, 312-321. doi: 10.1029/2007GL030658

Wunsch, C., and Ferrari, R. (2004). Vertical mixing, energy, and the general circulation of the ocean. Annu. Rev. Fluid Mech. 36, 281-314. doi: 10.1146/annurev.fluid.36.050802.122121

Zhang, W., Hanebuth, T. J., and Stöber, U. (2016). Short-term sediment dynamics on a meso-scale contourite drift (off NW Iberia): impacts of multi-scale oceanographic processes deduced from the analysis of mooring data and numerical modelling. Mar. Geol. 378, 81-100. doi: 10.1016/j.margeo.2015.12.006

Conflict of Interest: The authors declare that the research was conducted in the absence of any commercial or financial relationships that could be construed as a potential conflict of interest.

Copyright (๑) $2020 \mathrm{Al}$ Senafi and Anis. This is an open-access article distributed under the terms of the Creative Commons Attribution License (CC BY). The use, distribution or reproduction in other forums is permitted, provided the original author(s) and the copyright owner(s) are credited and that the original publication in this journal is cited, in accordance with accepted academic practice. No use, distribution or reproduction is permitted which does not comply with these terms. 